\title{
$(+)-\left[{ }^{18}\right.$ F]Flubatine as a novel $\alpha 4 \beta 2$ nicotinic acetylcholine receptor PET ligand-results of the first-in-human brain imaging application in patients with $\beta$-amyloid PET-confirmed Alzheimer's disease and healthy controls
}

\author{
Solveig Tiepolt ${ }^{1}$ (D) $\cdot$ Georg-Alexander Becker ${ }^{1} \cdot$ Stephan Wilke $^{1} \cdot$ Diego Cecchin $^{2} \cdot$ Michael Rullmann $^{1}$. \\ Philipp M. Meyer ${ }^{1}$. Henryk Barthel ${ }^{1}$. Swen Hesse ${ }^{1}$. Marianne Patt ${ }^{1}$ - Julia Luthardt ${ }^{1}$. Gudrun Wagenknecht ${ }^{3}$. \\ Bernhard Sattler ${ }^{1} \cdot$ Winnie Deuther-Conrad ${ }^{4}$ • Friedrich-Alexander Ludwig ${ }^{4}$. Steffen Fischer ${ }^{4} \cdot$ Hermann-Josef Gertz $^{5}$. \\ René Smits ${ }^{6}$. Alexander Hoepping ${ }^{6} \cdot$ Jörg Steinbach $^{7} \cdot$ Peter Brust ${ }^{4} \cdot$ Osama Sabri $^{1}$
}

Received: 7 May 2020 / Accepted: 7 September 2020 / Published online: 16 September 2020

(C) The Author(s) 2020

\begin{abstract}
Purposes We present the first in-human brain PET imaging data of the new $\alpha 4 \beta 2$ nicotinic acetylcholine receptor (nAChR)targeting radioligand $(+)-\left[{ }^{18} \mathrm{~F}\right]$ Flubatine. Aims were to develop a kinetic modeling-based approach to quantify $(+)-\left[{ }^{18} \mathrm{~F}\right]$ Flubatine and compare the data of healthy controls (HCs) and patients with Alzheimer's disease (AD); to investigate the partial volume effect (PVE) on regional (+)- $\left[{ }^{18} \mathrm{~F}\right]$ Flubatine binding; and whether $(+)-\left[{ }^{18} \mathrm{~F}\right]$ Flubatine binding and cognitive test data respective $\beta$ amyloid radiotracer accumulation were correlated.

Methods We examined $11 \mathrm{HCs}$ and 9 mild AD patients. All subjects underwent neuropsychological testing and $\left[{ }^{11} \mathrm{C}\right] \mathrm{PiB}$ PET/MRI examination. (+)-[ ${ }^{18}$ F]Flubatine PET data were evaluated using full kinetic modeling and regional as well as voxel-based analyses. Results With 270-min p.i., the unchanged parent compound amounted to $97 \pm 2 \%$. Adequate fits of the time-activity curves were obtained with the 1 tissue compartment model (1TCM). (+)- $\left[{ }^{18} \mathrm{~F}\right]$ Flubatine distribution volume (binding) was significantly

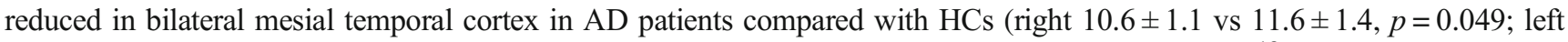
$11.0 \pm 1.1$ vs $12.2 \pm 1.8, p=0.046$; one-sided $t$ tests each). PVE correction increased not only $(+)-\left[{ }^{18} \mathrm{~F}\right]$ Flubatine binding of approximately $15 \%$ but also standard deviation of $0.4-70 \%$. Cognitive test data and $(+)-\left[{ }^{18} \mathrm{~F}\right]$ Flubatine binding were significantly correlated in the left anterior cingulate, right posterior cingulate, and right parietal cortex ( $r>0.5, p<0.05$ each). In $\mathrm{AD}$ patients, $(+)-\left[{ }^{18} \mathrm{~F}\right]$ Flubatine binding and $\left[{ }^{11} \mathrm{C}\right] \mathrm{PiB}$ standardized uptake value ratios were negatively correlated in several regions; whereas in $\mathrm{HCs}$, a positive correlation between cortical $(+)-\left[{ }^{18} \mathrm{~F}\right]$ Flubatine binding and $\left[{ }^{11} \mathrm{C}\right] \mathrm{PiB}$ accumulation in the white matter was found. No adverse event related to $(+)-\left[{ }^{18}\right.$ F]Flubatine occurred.

Conclusion (+)- $\left[{ }^{18} \mathrm{~F}\right]$ Flubatine is a safe and stable PET ligand. Full kinetic modeling can be realized by $1 \mathrm{TCM}$ without metabolite correction. $(+)-\left[{ }^{18} \mathrm{~F}\right]$ Flubatine binding affinity was high enough to detect group differences. Of interest, correlation between white
\end{abstract}

Solveig Tiepolt, Georg-Alexander Becker, Peter Brust and Osama Sabri contributed equally to this work.

This article is part of the Topical Collection on Neurology

The study was registered by the European Union Drug Regulating Authorities Clinical Trials Database (https://eudract.ema.europa.eu) and has the following Eudra-CT-No. 2012-003473-26.

Electronic supplementary material The online version of this article (https://doi.org/10.1007/s00259-020-05029-w) contains supplementary material, which is available to authorized users.

Solveig Tiepolt

Solveig.tiepolt@medizin.uni-leipzig.de

Extended author information available on the last page of the article 
matter $\beta$-amyloid PET uptake and $(+)-\left[{ }^{18} \mathrm{~F}\right]$ Flubatine binding indicated an association between white matter integrity and availability of $\alpha 4 \beta 2 \mathrm{nAChRs}$. Overall, (+)-[ $\left.{ }^{18} \mathrm{~F}\right]$ Flubatine showed favorable characteristics and has therefore the potential to serve as $\alpha 4 \beta 2 \mathrm{nAChR}$-targeting PET ligand in further clinical trials.

Keywords (+)- $\left[{ }^{18} \mathrm{~F}\right]$ Flubatine $\left[(+)-\left[{ }^{18} \mathrm{~F}\right] \mathrm{NCFHEB}\right] \cdot \mathrm{PET} \cdot \alpha 4 \beta 2$ nicotinic acetylcholine receptors $\cdot$ Human brain $\cdot$ Kinetic modeling

\section{Introduction}

The cerebral cholinergic system plays an important role for attention, cognition, and addiction, mainly by modulation of other neurotransmitter systems (e.g., dopaminergic system) [1]. In this context, the nicotinic acetylcholine receptors (nAChRs) are of particular interest. In the human brain, the $\alpha 4 \beta 2$ subtype is the most frequent nAChR subtype. First, in vivo estimations of the distribution of nAChRs were performed by Nordberg et al. [2] using the positron emission tomography (PET) tracer $\left[{ }^{11} \mathrm{C}\right]$ nicotine. As the retention of $\left[{ }^{11} \mathrm{C}\right]$ nicotine in the brain is co-determined by blood flow, blood brain barrier transport, and unspecific binding [3], a precise correlation of changes in $\left[{ }^{11} \mathrm{C}\right]$ nicotine accumulation with the nAChR availability was impossible. This problem was solved by 3-pyridylether derivatives (i.e., $2-\left[{ }^{18} \mathrm{~F}\right] \mathrm{FA}-$ 85380, 6- $\left[{ }^{18} \mathrm{~F}\right] \mathrm{FA}-85380$, and 5-[ $\left.\left.{ }^{123} \mathrm{I}\right] \mathrm{IA}-85380\right)$. However, their slow kinetics hamper their application especially in a routine clinical setting [4]. Thus, new PET ligands with more favorable characteristics have been developed. These radioligands are all derivatives of homoepibatidine, epibatidine, or 3-pyridylether derivatives [4]. Results of first applications in humans were published for $(-)-\left[{ }^{18} \mathrm{~F}\right]$ Flubatine, $\left[{ }^{18} \mathrm{~F}\right] \mathrm{AZAN}$, and $\left[{ }^{18} \mathrm{~F}\right] \mathrm{XTRA}$ showing favorable data for dosimetry and image quality as well as fast kinetics [5-7]. However, $\left[{ }^{18} \mathrm{~F}\right]$ AZAN and $\left[{ }^{18} \mathrm{~F}\right] \mathrm{XTRA}$ are significantly metabolized [7]; $\left(-\left[{ }^{18} \mathrm{~F}\right]\right.$ Flubatine on the other hand showed only a low amount of metabolites $[5,8,9]$. Due to inter-individual variability, the application of a reference region was often required to detect $\alpha 4 \beta 2 \mathrm{nAChR}$ differences between patients and healthy controls [9-15].

$(+)-\left[{ }^{18} \mathrm{~F}\right]$-Flubatine is the enantiomer of $(-)-\left[{ }^{18} \mathrm{~F}\right]$ Flubatine. Preclinical data showed a higher binding affinity and a similar metabolism but a slower kinetics for $(+)-\left[{ }^{18} \mathrm{~F}\right]$ Flubatine compared with $(-)-\left[{ }^{18} \mathrm{~F}\right]$ Flubatine $[16,17]$. Therefore, it was assumed that the analysis of cerebral $(+)-\left[{ }^{18} \mathrm{~F}\right]$ Flubatine distribution works without application of a reference region.

It is known from neuropathological studies that an alteration of the cholinergic system with loss of $\alpha 4 \beta 2 \mathrm{nAChRs}$ occurs in patients with Alzheimer's dementia (AD) [18, 19]. Several PET and SPECT studies using 2-[ ${ }^{18}$ F]FA-85380 or $5-\left[{ }^{123} \mathrm{I}\right] \mathrm{IA}-85380$ revealed a reduction of $\alpha 4 \beta 2 \mathrm{nAChRs}$ in both $\mathrm{AD}$ and $\mathrm{MCI}$ subjects compared with HCs in various brain regions [9-13].
Primary aim of this study was to evaluate kinetic modelbased approaches to quantify the dynamic $(+)-\left[{ }^{18} \mathrm{~F}\right]$ Flubatine data and to compare the data of HCs with the data of patients with $\mathrm{AD}$. The primary analysis was performed without the use of a reference region to prove that the $(+)-\left[{ }^{18} \mathrm{~F}\right]$ Flubatine binding affinity was high enough to detect differences. Secondary aims of this study were to investigate (i) whether cortical atrophy affected the regional $(+)-\left[{ }^{18} \mathrm{~F}\right]$ Flubatine binding, (ii) whether $(+)-\left[{ }^{18} \mathrm{~F}\right]$ Flubatine binding was correlated with $\operatorname{cog}$ nitive test data, and (iii) whether $(+)-\left[{ }^{18}\right.$ F]Flubatine showed a correlation to $\beta$-amyloid $(A \beta)$ plaques.

\section{Methods and material}

\section{Participants}

All study participants were non-smokers, drug-free for any kind of centrally acting medication, and had no history of neurological or psychiatric illnesses except those with $A D$ who were recruited as patient cohort. All subjects underwent a clinical assessment including a thorough neuropsychological testing. HCs were required to achieve a Clinical Dementia Rating (CDR) score of zero and psychometric test results within an interval of one standard deviation from the mean value (adjusted for age and education). Patients with mild to moderate $\mathrm{AD}$ were characterized by a progressive cognitive decline with DSM-IV criteria for dementia and probable Alzheimer's disease according to the NINCDS-ADRDA criteria, furthermore a Mini Mental State Examination (MMSE) score between 20 and 26 and a CDR of 0.5 or 1.0 . All subjects underwent a $\left[{ }^{11} \mathrm{C}\right] \mathrm{PiB}$ PET/MRI examination on a simultaneous PET/MRI system (Biograph mMR, Siemens Healthcare, Erlangen, Germany). As the trials of $A \beta$-targeting PET tracers showed that only $63-66 \%$ of patients with the clinical diagnosis of probable AD were histopathologically $A \beta$ plaque positive [20-22], we decided to implement $A \beta$ PET imaging using $\left[{ }^{11} \mathrm{C}\right]$ Pittsburgh Compound $\mathrm{B}(\mathrm{PiB})$ in our screening procedure. All HCs had to be $\mathrm{A} \beta$ PET negative (Supplementary Figure 1), with the MRI not revealing any pathological findings. In the $A D$ patients, a positive $A \beta$ PET (Supplementary Figure 1) scan and a medial temporal lobe atrophy of Scheltens score $\geq 1$ [23] were required. Overall, we recruited 30 participants (14 patients with clinical diagnosis of mild $\mathrm{AD}$ and $16 \mathrm{HCs}$ ). We had 9 drop-outs because of 
withdrawn consent $(N=2 \mathrm{HCs})$ and abnormal $\beta$-amyloid PET/MRI findings (4 patients with the clinical diagnosis of mild AD were $\beta$-amyloid PET negative, one $\mathrm{HC}$ was $\beta$ amyloid PET positive, another HC showed a large cerebral cyst, and a third HC an old cerebral hemorrhage). Furthermore, one patient had to be excluded because of severe motion artifacts in the brain scans. Thus, the final study population consisted of $9 \mathrm{AD}$ patients and $11 \mathrm{HCs}$. The demographic data are summarized in Table 1.

\section{Neuropsychological testing}

Global cognitive performance was tested using MMSE, CDR, and DemTect. Attention was measured by A-K-T test (German: "Alters-Konzentrations-Test"). All subtests of the Consortium to Establish a Registry for Alzheimer's Disease (CERAD) battery were assessed including TMT-A as well as immediate and delayed memory tests of the Wechsler Memory Scale (WMS). Furthermore, the Geriatric Depression Scale (GDS) scores were acquired.

\section{PET and MR image acquisition and processing}

The $\left[{ }^{11} \mathrm{C}\right] \mathrm{PiB}$ PET/MRI examination included a 3-T brain MR imaging with the following sequences: standardized 3D T1w MPRAGE, T2 $\mathrm{w}, \mathrm{T} 2 * \mathrm{w}$ and SWI in various planes (axial, coronal, sagittal), $\mathrm{T} 2 \mathrm{w} 3 \mathrm{D}$ volumetric sequence (SPACE), and a DIXON sequence.

Dynamic (+)- $\left[{ }^{18} \mathrm{~F}\right]$ Flubatine brain PET data were obtained with a stand-alone PET system (ECAT Exact HR+, CTI/ Siemens, Knoxville, USA) in 3D mode following a slow intravenous injection of $287 \pm 12 \mathrm{MBq}(+)-\left[{ }^{18} \mathrm{~F}\right]$ Flubatine. The specific activity at the time of injection was $8.16 \times 10^{5} \pm$ $1.67 \times 10^{5} \mathrm{GBq} / \mathrm{mmol}$ in $\mathrm{HC}$ subjects and $7.88 \times 10^{5} \pm$ $9.45 \times 10^{4} \mathrm{GBq} / \mathrm{mmol}$ in $\mathrm{AD}$ patients $(p=0.657)$. The injected mass at the time of injection was in HCs $0.074 \pm$ $0.013 \mu \mathrm{g}$ and in $\mathrm{AD}$ patients $0.076 \pm 0.087 \mu \mathrm{g}(p=0.679)$. Emission data consisted of one dynamic scan (0--90-min p.i., 23 frames) and three subsequent scans (120-150-min p.i., 180--210-min p.i., 240-270-min p.i., 6 frames per scan). For attenuation correction, a $10-\min { }^{68} \mathrm{Ge}$-transmission scan was performed prior to tracer application. Furthermore, all standard corrections as implemented by the vendor were applied (scatter, random events, radioactive decay, and dead time). Reconstruction of the PET data was performed by the ordered subset expectation maximization method with 10 iterations and 16 subsets into a voxel size of $2.6 \times 2.6 \times 2.4 \mathrm{~mm}$.

Prior to kinetic analysis, the PET data were pre-processed using the PMOD software (PMOD technologies Ltd., Zürich, Switzerland, version 3.5). The individual MRI data were spatially reoriented onto a standard brain data set similar to the Talairach space. Thirty-six volumes of interest (VOIs) were manually drawn on three consecutive slices of the reoriented individual 3D T1w MPRAGE data (Supplementary Figure 2). The PET data was corrected for motion artifacts using Statistic Parametric Mapping 12 (SPM-Software; Wellcome Trust Centre for Neuroimaging, University College London) as described in detail elsewhere [9]. PMOD was used to co-register the dynamic PET data with the individual T1 MPRAGE MRI in order to create the time-activity curves (TACs) for the kinetic analysis.

\section{Blood sampling and plasma data analyses}

Arterial blood samples were obtained from each subject. Thirty minutes before the radiotracer injection, a $10 \mathrm{~mL}$ sample was taken. Twelve to sixteen $2-\mathrm{mL}$ samples were drawn in the first $3 \mathrm{~min}$ following injection and further samples until 270-min p.i.. All samples were centrifuged to separate blood plasma from the remnants. The radioactivity in plasma aliquots was measured using a gamma counter (COBRA, Packard Instrument Company, Meriden, CT, USA) and corrected for decay of F-18.

To estimate the non-metabolized parent fraction of the tracer, plasma was obtained from arterial blood samples and deproteinized by addition of acetonitrile (1:2) followed by
Table 1 Demographic data of the study population

\begin{tabular}{llll}
\hline & Healthy controls & Patients with AD & $p$ \\
\hline Male/female & $4 / 7$ & $2 / 7$ & - \\
Age [years] & $67 \pm 4$ & $67 \pm 25$ & 0.96 \\
Apo E4 positivity (heterozygote/homozygote) & $2 / 0$ & $4 / 1$ & n.s. \\
MTLA & $0.5 \pm 0.7$ & $1.7 \pm 0.7$ & 0.001 \\
MMSE score & $30 \pm 0.5$ & $25 \pm 1.4$ & $<0.001$ \\
DemTect score & $15.8 \pm 2.4$ & $8.8 \pm 3.1$ & $<0.001$ \\
A-K-T-PR* score & $87.9 \pm 20.9$ & $62.5 \pm 28.3$ & 0.038 \\
\hline
\end{tabular}

$A-K-T-P R$ Alters-Konzentrations-Test, percentile ranks; $A D$ Alzheimer's disease; MTLA medial temporal lobe atrophy according to [23]; Values are given as mean value \pm standard deviation

${ }^{\#}$ In one patient with $\mathrm{AD}$ and one $\mathrm{HC}$, the apolipoprotein (Apo) E4 status was not ascertained

*In one AD patient, the A-K-T-PR was not ascertained 
centrifugation at $10,000 \mathrm{RPM}(6000 \times g)$ for $10 \mathrm{~min}$. The plasma samples were then analyzed by HPLC. The HPLC system used consisted of a gradient pump (P580, Dionex, Sunnyvale, CA), equipped with an UV and radioactivity detector (UV170D, Dionex, Sunnyvale, CA and GABI Star, Raytest, Straubenhardt, Germany, respectively), and a fraction sampling device (Foxy Junior, Isco, Lincoln, NE).

The amount of parent compound was determined by dividing the peak area corresponding to unchanged tracer by the total sum of all peak areas occurring in the chromatogram. For the late time points of sampling (i.e., 210- and 270-min p.i.), the eluate from the HPLC column was collected in $1.5 \mathrm{~mL}$ fractions by means of a fraction sampling device and the containing radioactivity was determined by gamma counting. The amount of parent compound was then calculated by dividing the sum of the activity contained within the fractions corresponding to the unchanged tracer by the sum of all fractions collected. The plasma-free fraction of tracer $f_{\mathrm{p}}$ was measured for each subject by ultrafiltration [8] using the $10-\mathrm{mL}$ blood sample taken $30 \mathrm{~min}$ before the radiotracer injection.

\section{Kinetic data analysis and modeling}

1- and 2-tissue compartment models (TCM) were applied to analyze the time-activity curves (TAC). As the examination of the plasma probes did not reveal any relevant metabolites (Fig. 1), arterial input functions without metabolite correction were used. We applied the Akaike's information criterion with correction for small sample sizes on the 90-min data of (+)- $\left[{ }^{18} \mathrm{~F}\right]$ Flubatine $[24,25]$. Model-based receptor parameters were the total distribution volume $V_{\mathrm{T}}\left(\mathrm{ml} / \mathrm{cm}^{-3}\right), V_{\mathrm{T}} / f_{\mathrm{p}}(\mathrm{ml} /$ $\mathrm{cm}^{-3}$ ) and the distribution volume ratio (DVR) with the occipital cortex as reference region.

$V_{\mathrm{T}}$ is a region-dependent, linear function of the receptor density available for the $\operatorname{tracer} B_{\text {avail }}$, i.e., in case of the $2 \mathrm{TCM}$

$V_{\mathrm{T}}=\frac{K_{1}}{k_{2}}\left(1+\frac{f_{\mathrm{ND}} B_{\text {avail }}}{K_{\mathrm{D}}}\right)$

where $K_{1}, k_{2}$ describe the transport into and out of the first (nondisplaceable) tissue compartment, $f_{\mathrm{ND}}$ the free fraction of tracer in the first tissue compartment, and $K_{\mathrm{D}}$ the dissociation constant of the receptor-ligand complex [26].

The distribution volume ratio DVR is under the assumptions that (1) the reference region is void of receptors, and (2) the nondisplaceable distribution volume $V_{\mathrm{ND}}=K_{1} / k_{2}$ is the same in target and reference region, given by

$\mathrm{DVR}=\frac{V_{\mathrm{T}}}{V_{N D}}=1+\frac{f_{\mathrm{ND}} \cdot B_{\text {avail }}}{K_{\mathrm{D}}}$.

Further, Logan's graphical analysis was applied to compute voxel-wise parametric images of $V_{\mathrm{T}} / f_{\mathrm{p}}$ in PMOD. Parametric images were spatially normalized in SPM12 by applying a non-linear transformation calculated based on the individual T1 MRI data. Smoothing was performed with an 8mm Gaussian kernel.

\section{Reference region}

$(+)-\left[{ }^{18} \mathrm{~F}\right]$ Flubatine binding was quantified by the total distribution volume, a linear function of the local receptor density. Smaller $(+)-\left[{ }^{18} \mathrm{~F}\right]$ Flubatine binding differences between $\mathrm{AD}$ patients and HCs might not reach significance because of inter-individual variability of $\mathrm{nAChRs}$ availability especially in a small sample size like ours. The implementation of a reference region is a usual approach to address this problem. As already noted, however, by definition, a reference region has to be void of receptors. Unfortunately, $\alpha 4 \beta 2$ nAChRs are ubiquitous in the human brain. Thus, we carefully considered to possibly use a "pseudoreference" region and chose for this purpose the bilateral occipital cortex, still being aware that this procedure has its limitations.

\section{Partial volume effect correction}

To estimate the partial volume effect (PVE) on the (+)- $\left[{ }^{18} \mathrm{~F}\right]$ Flubatine PET data, we additionally performed a region-based voxel-wise (RBV) partial volume effect correction as recently performed by our group for $(-)-\left[{ }^{18} \mathrm{~F}\right]$ Flubatine PET data in AD and HCs (Sabri et al., 2018; Thomas et al., 2016; Thomas et al., 2011). Here, the PVE-corrected timeactivity curves $0-90$-min p.i. were used for the kinetic analysis with a 1-tissue compartment model (1TCM) resulting in PVE-corrected distribution volumes $\left(V_{\mathrm{T}} / f \mathrm{p}_{\mathrm{PVEC}}\right)$.

\section{Determination of the cortical thickness}

To investigate whether cortical thickness has an influence on the $(+)-\left[{ }^{18} \mathrm{~F}\right]$ Flubatine PET data, the Desikan-Killiany cortical

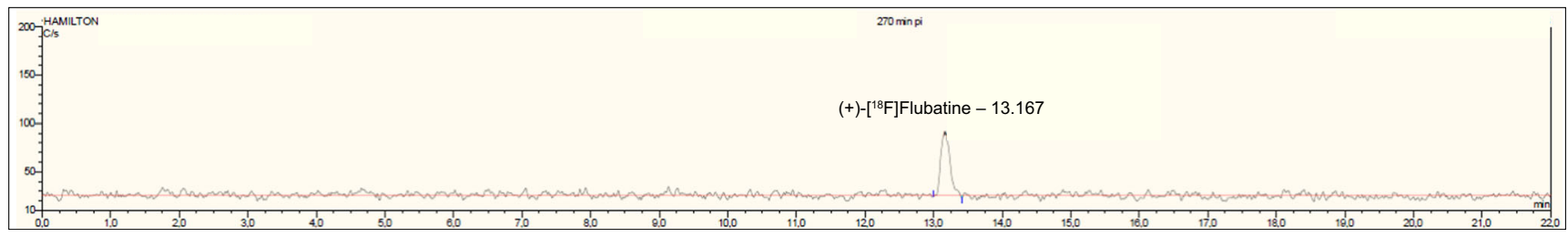

Fig. 1 Metabolism of $(+)-\left[{ }^{18}\right]$ Flubatine as measured in blood over time: over $97 \%$ unchanged parent compound at 270-min p.i.. The retention time (min) of a peak is given adjacent to the peak identification 
labelling protocol [27] was used. The isotropic $\left(1 \mathrm{~mm}^{3}\right) \mathrm{T} 1-$ weighted MR images were processed using FreeSurfer (v. 5.3) software (http://surfer.nmr.mgh.harvard.edu). After removing of the non-brain tissue and transformation onto the Talairach space, subcortical white matter and deep gray matter volumetric structures were segmented and normalized. Then, gray matter-white matter boundaries were calculated and parcellation of the cerebral cortex into units based on the gyral and sulcal structures was performed. The distance between the white matter and the pia mater was used as the thickness of each region [28].

\section{Statistical analyses}

Statistical analyses were performed with MATLAB (version 7.13, The MathWorks, Natick, MA, USA) and IBM SPSS statistic software (version 24).

As a reduction of $\alpha 4 \beta 2$ nAChRs in $\mathrm{AD}$ patients can be assumed based on the results of our earlier studies $[9,10,13]$ and autoradiographic findings, one-sided $t$ tests were performed. The entire region set was used only for kinetic modeling. To compare (+)- $\left[{ }^{18} \mathrm{~F}\right]$ Flubatine binding between $\mathrm{AD}$ patients and HCs, 10 regions (i.e., bilateral frontal, mesial temporal, parietal, anterior cingulate cortex (ACC), and posterior cingulate cortex (PCC)) were used. These candidate regions were chosen according to our previous results $[9,10,13]$. A correction for multiple testing was not applied. $p<0.05$ was considered as significant [29], unless otherwise stated.

For correlation analysis between cortical thickness and $V_{\mathrm{T}} /$ $f_{\mathrm{p}}$, we used partial correlations with age and sex as covariates. We correlated the cortical thickness and $(+)-\left[{ }^{18}\right.$ F]Flubatine binding $\left(V_{\mathrm{T}} / f_{\mathrm{p}}\right)$ of the mesial temporal cortices and left precuneus as these regions showed significantly different (+)- $\left[{ }^{18} \mathrm{~F}\right]$ Flubatine binding between AD patients and HCs. For this, the cortical thicknesses of the parahippocampal, entorhinal, fusiform, and inferior temporal regions of the Desikan-Killiany atlas were averaged and correlated with the $V_{\mathrm{T}} / f_{\mathrm{p}}$ values of the mesial temporal ROI.

Correlation analyses regarding cognitive test results and $(+)-\left[{ }^{18} \mathrm{~F}\right]$ Flubatine binding were only performed for regions with significantly different $(+)-\left[{ }^{18} \mathrm{~F}\right]$ Flubatine binding between AD patients and HCs. To consider age, sex, and educational differences, the raw data of the CERAD subtests were converted into $z$ scores; and for the A-K-T data, the percentile ranks (PR) were used to consider age and gender differences. Thus, Pearson's correlations without covariates were assessed between CERAD z scores and $(+)-\left[{ }^{18} \mathrm{~F}\right]$ Flubatine binding $\left(V_{\mathrm{T}} /\right.$ $f_{\mathrm{p}}$ ) and partial correlations with education as covariate were calculated for correlation analyses between A-K-T-PR and $V_{\mathrm{T}} / f_{\mathrm{p}}$. For partial correlations between WMS, DemTect or GDS, and $V_{\mathrm{T}} / f_{\mathrm{p}}$, adjustment for age, sex, and education was carried out.
To correlate (+)- $\left[{ }^{18} \mathrm{~F}\right]$ Flubatine binding and $\left[{ }^{11} \mathrm{C}\right] \mathrm{PiB}$ uptake, seven regions (i.e., frontal, lateral temporal, parietal, occipital, anterior, and posterior cingulate cortex as well as white matter) were selected. These regions are established to investigate $\beta$-amyloid PET tracer uptake which is intense in cortical gray matter in $\mathrm{AD}$ patients and in white matter in HCs [30, 31].

For voxel-based comparisons performed using SPM 12, we used two-sample $t$ tests with gender as covariate, $p<0.001$ (uncorrected) as significance level, no global normalization, and $k=10$ voxels as minimal cluster volume.

\section{Results}

\section{$(+)-\left[{ }^{18}\right.$ F]Flubatine PET kinetic analyses and model selection}

The free fraction of $(+)-\left[{ }^{18} \mathrm{~F}\right]$ Flubatine in plasma $f_{\mathrm{p}}$ was high and showed only small inter-individual variations (HCs 0.858 $\pm 0.020(n=11)$, ADs $0.869 \pm 0.020(n=9))$ with no differences between the groups $(p=0.251)$. The 1TCM and 2TCM could both be applied to describe the kinetics of $(+)-\left[{ }^{18} \mathrm{~F}\right]$ Flubatine in brain tissue over time ranges of $0-90$ min p.i. to 0-270-min p.i. and to compute receptor parameters. $V_{\mathrm{T}} / f_{\mathrm{p}}$ in all cortical regions could be reliably estimated from 0- to 90-min p.i. PET data. The Akaike information criterion (AIC) showed lower values for the 2TCM in the majority of HCs. The mean AIC values of the $11 \mathrm{HCs}$ were in the right thalamus: $1 \mathrm{TCM}-24.73 \pm 10.19 ; 2 \mathrm{TCM}-37.26$ \pm 16.82 ; in the left thalamus: $1 \mathrm{TCM}-25.36 \pm 10.14 ; 2 \mathrm{TCM}$ $-33.91 \pm 16.75$; in the right frontal cortex $1 \mathrm{TCM}-31.47 \pm$ 19.24; $2 \mathrm{TCM}-61.02 \pm 17.93$; in the left frontal cortex: $1 \mathrm{TCM}-34.02 \pm 14.09 ; 2 \mathrm{TCM}-59.98 \pm 19.08$; in the corpus callosum posterior: $1 \mathrm{TCM}-39.51 \pm 15.58 ; 2 \mathrm{TCM}-49.58 \pm$ 12.27. Thus, for $(+)-\left[{ }^{18} \mathrm{~F}\right]$ Flubatine, the tracer kinetics could successfully be described with 1TCM (Table 2, Fig. 2). In the supplement, 1TCM and 2TCM estimations of all 36 brain regions and the corresponding $V_{\mathrm{T}} / f_{\mathrm{p}}$ and $K_{1}$ values are presented (Supplementary Figure 3). Supplementary Figure 5 shows regional $V_{\mathrm{T}} / f_{\mathrm{p}}$ values of the a-priori regions, the $\alpha 4 \beta 2$ nAChRs rich thalami, and the corpus callosum posterior as region with lowest $\alpha 4 \beta 2 \mathrm{nAChR}$ density separately for HCs and patients with $\mathrm{AD}$ for different scan durations. Supplementary Table 1 summarizes the correlation analysis between regional $V_{\mathrm{T}} / f_{\mathrm{p}}$ values and injected mass in HCs for the a-priori regions.

\section{(+)-[ $\left.{ }^{18} \mathrm{~F}\right]$ Flubatine rate constants $K_{1}$ and $k_{2}$ estimated by $1 \mathrm{TCM}$}

We found a significantly different influx rate $K_{1}$ between HCs and $\mathrm{AD}$ patients in the bilateral mesial temporal cortex (right: 
Table 2 Quantitative $(+)-\left[{ }^{18}\right.$ F]Flubatine PET parameters in bilateral brain regions of the healthy controls

\begin{tabular}{|c|c|c|c|c|}
\hline \multirow[t]{2}{*}{ Brain region } & \multicolumn{2}{|c|}{ 0-90-min p.i. } & \multicolumn{2}{|c|}{ 0-270-min p.i. } \\
\hline & $\begin{array}{l}V_{\mathrm{T}} / f_{\mathrm{p}} \\
(1 \mathrm{TCM})\end{array}$ & $\begin{array}{l}V_{\mathrm{T}} / f_{\mathrm{p}} \\
(2 \mathrm{TCM})\end{array}$ & $\begin{array}{l}V_{\mathrm{T}} / f_{\mathrm{p}} \\
(1 \mathrm{TCM})\end{array}$ & $\begin{array}{l}V_{\mathrm{T}} / f_{\mathrm{p}} \\
(2 \mathrm{TCM}\end{array}$ \\
\hline Frontal cortex & $11.8 \pm 1.7$ & $12.0 \pm 1.7$ & $12.8 \pm 1.7$ & $12.6 \pm 1.5$ \\
\hline Lateral temporal cortex & $11.9 \pm 1.5$ & $12.1 \pm 1.5$ & $12.6 \pm 1.6$ & $12.5 \pm 1.5$ \\
\hline Mesial temporal cortex & $11.9 \pm 1.5$ & $12.1 \pm 1.6$ & $13.2 \pm 1.8$ & $13.2 \pm 1.7$ \\
\hline Parietal cortex & $12.3 \pm 1.3$ & $12.6 \pm 1.2$ & $12.9 \pm 1.8$ & $12.7 \pm 1.7$ \\
\hline Occipital cortex & $10.6 \pm 1.3$ & $11.0 \pm 1.1$ & $11.7 \pm 1.3$ & $11.6 \pm 1.3$ \\
\hline Anterior cingulate cortex & $13.0 \pm 1.8$ & $13.4 \pm 1.8$ & $14.7 \pm 2.5$ & $14.3 \pm 2.4$ \\
\hline Posterior cingulate cortex & $12.5 \pm 1.8$ & $12.9 \pm 1.7$ & $14.0 \pm 2.2$ & $13.7 \pm 2.1$ \\
\hline Caudate nucleus & $14.2 \pm 2.1$ & $14.5 \pm 2.0$ & $16.1 \pm 2.7$ & $15.4 \pm 2.4$ \\
\hline Putamen & $15.8 \pm 2.5$ & $16.7 \pm 2.6$ & $19.3 \pm 3.2$ & $18.3 \pm 2.7$ \\
\hline Thalamus & $47.6 \pm 11.3$ & $47.8 \pm 11.0$ & $52.4 \pm 13.0$ & $48.3 \pm 10.7$ \\
\hline White matter & $17.4 \pm 3.4$ & $20.3 \pm 5.1$ & $21.7 \pm 5.7$ & $21.2 \pm 5.6$ \\
\hline Pons/midbrain & $17.6 \pm 3.6$ & $18.0 \pm 3.7$ & $19.1 \pm 3.8$ & $19.0 \pm 3.7$ \\
\hline Cerebellar cortex & $14.9 \pm 3.0$ & $15.0 \pm 2.9$ & $16.0 \pm 3.2$ & $15.7 \pm 3.0$ \\
\hline Corpus callosum anterior & $9.0 \pm 1.3$ & $9.5 \pm 1.3$ & $9.5 \pm 1.4$ & $9.6 \pm 1.4$ \\
\hline Corpus callosum posterior & $8.9 \pm 1.7$ & $9.3 \pm 1.6$ & $9.4 \pm 2.1$ & $9.2 \pm 1.9$ \\
\hline Hypothalamus & $19.9 \pm 3.7$ & $20.3 \pm 3.5$ & $22.6 \pm 5.3$ & $21.3 \pm 4.7$ \\
\hline Insula & $13.3 \pm 1.9$ & $13.7 \pm 1.6$ & $15.0 \pm 2.3$ & $14.8 \pm 2.2$ \\
\hline Midbrain/substantia nigra & $20.0 \pm 3.8$ & $20.7 \pm 4.2$ & $22.6 \pm 4.6$ & $22.4 \pm 4.6$ \\
\hline Hippocampus & $12.1 \pm 1.8$ & $12.6 \pm 1.7$ & $14.1 \pm 2.1$ & $13.7 \pm 1.8$ \\
\hline Amygdala & $11.6 \pm 1.3$ & $11.5 \pm 1.3$ & $11.9 \pm 1.2$ & $11.7 \pm 1.2$ \\
\hline
\end{tabular}

$V_{\mathrm{T}} / f_{\mathrm{p}}$ total distribution volume divided by the free fraction in plasma; ITCM one-tissue compartment model, $2 T C M$ Two-tissue compartment model. Values are given as mean value \pm standard deviation
HCs $0.29 \pm 0.03$, ADs $0.25 \pm 0.04, p=0.02$; left: HCs $0.30 \pm$ 0.04 , ADs $0.26 \pm 0.05, p=0.03$ ). Furthermore, we obtained significantly different washout constants $k_{2}$ in the right frontal (HCs $0.035 \pm 0.004$, ADs $0.032 \pm 0.004 ; p=0.047$ ), right mesial temporal (HCs $0.029 \pm 0.003$, ADs $0.027 \pm 0.003 ; p=$ 0.035 ), and left mesial temporal cortex (HCs $0.029 \pm 0.003$, ADs $0.026 \pm 0.003 ; p=0.045)$.

\section{$(+)-\left[{ }^{18}\right.$ F Flubatine binding $\left(V_{\mathrm{T}} / f_{\mathrm{p}}\right)$}

ROI-based analyses showed a significantly lower binding of (+)- $\left[{ }^{18} \mathrm{~F}\right]$ Flubatine in the AD patients compared with the HCs in the mesial temporal cortices (Table 3, Fig. 3). Voxel-based analyses showed larger clusters $(k>100$ voxels) of reduced $(+)-\left[{ }^{18} \mathrm{~F}\right]$ Flubatine binding in AD patients in the left-sided hippocampus, precuneus, and putamen and smaller clusters ( $k=30-100$ voxels) in the right anterior orbitofrontal cortex, right paracentral lobule, left anterior cingulate cortex, and left triangular inferior frontal gyrus (Table 4, Fig. 4).

\section{$(+)-\left[{ }^{18}\right.$ F Flubatine binding using a reference region}

Using the bilateral occipital cortex as reference region, the following regions showed significantly lower relative
(+)- $\left[{ }^{18} \mathrm{~F}\right]$ Flubatine DVRs in AD patients compared with HCs: right mesial temporal $(1.02 \pm 0.07$ vs. $1.09 \pm 0.06, p=$ $0.02)$, left mesial temporal $(1.07 \pm 0.05$ vs. $1.15 \pm 0.05, p=$ $0.001)$, and right parietal cortex $(1.13 \pm 0.07$ vs. $1.19 \pm 0.06$, $p=0.03)$ and a further region showed a trend: left frontal cortex $(1.08 \pm 0.03$ vs. $1.11 \pm 0.06, p=0.06)$, whereas left mesial temporal cortex survived correction for multiple testing.

\section{Partial volume effect correction of $(+)-\left[{ }^{18}\right.$ F]Flubatine PET data}

Applying a PVE correction, the (+)- $\left[{ }^{18} \mathrm{~F}\right]$ Flubatine binding $\left(V_{\mathrm{T}} / f_{\mathrm{p}}\right)$ mean values increased by approximately $14.6 \%$ (range $7.4-22.1 \%$ ) in the HC group and by approximately $17.1 \%$ (range $7.2-27.8 \%$ ) in the $\mathrm{AD}$ group while the standard

Fig. 2 One-tissue compartment model (1TCM) and two-tissue compartment model (2TCM) applied to 5 brain regions of one HC (90and 270-min data). PET activity measurements are given by points. Computed tracer concentrations in tissue are presented as lines (a). Mean parametric images (by Logan plots) of $(+)-\left[{ }^{18} \mathrm{~F}\right]$ Flubatine $\left(V_{\mathrm{T}} / f_{\mathrm{p}}\right)$ of the 11 healthy controls (HCs, top row) compared to the 9 patients with mild Alzheimer's disease (AD, bottom row). White arrows indicate the significantly lower binding of $(+)-\left[{ }^{18} \mathrm{~F}\right]$ Flubatine in the bilateral mesial temporal cortex in patients with $\mathrm{AD}(\mathbf{b})$ 

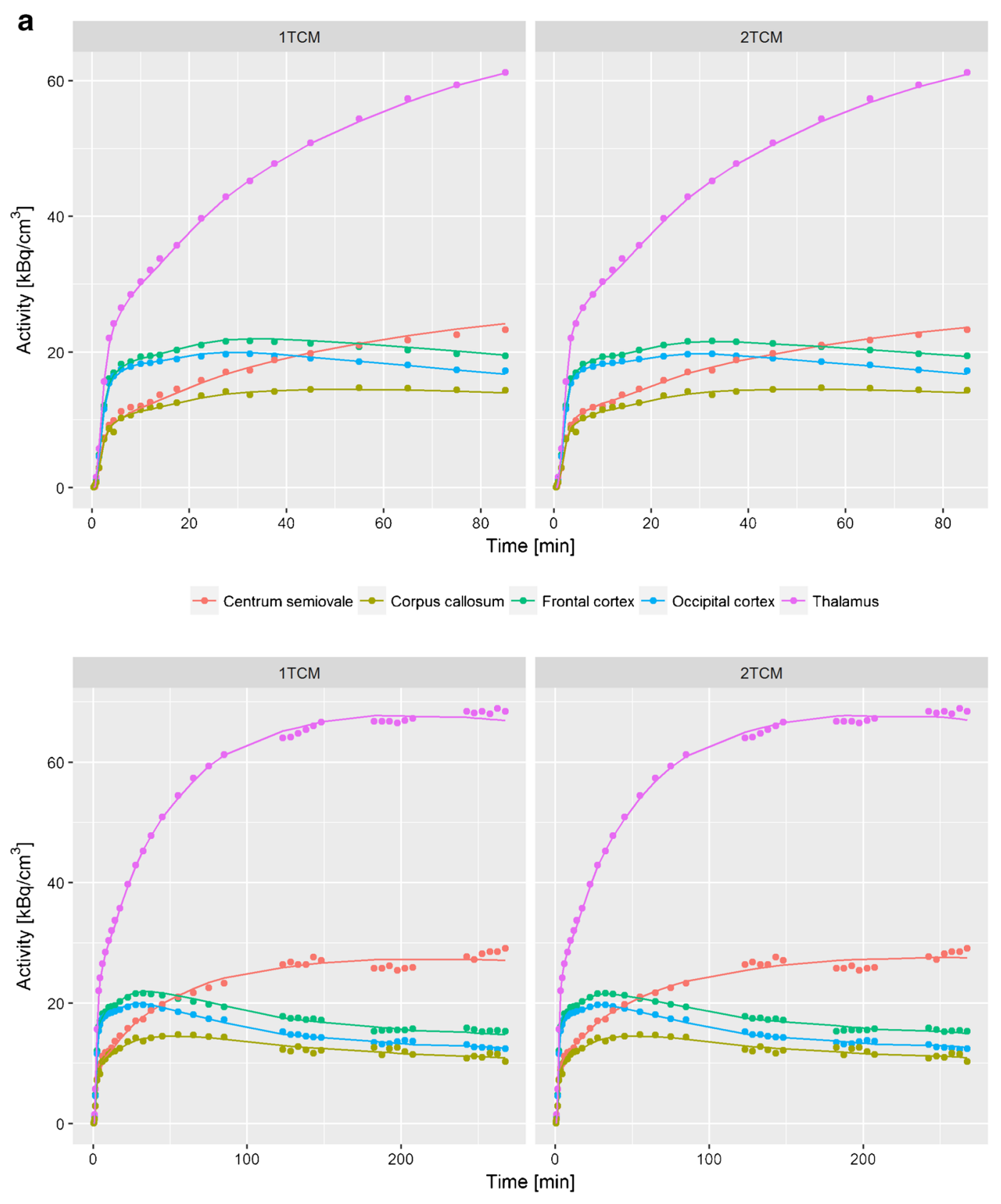

$\rightarrow$ Centrum semiovale $\rightarrow$ Corpus callosum $\rightarrow$ Frontal cortex $\rightarrow$ Occipital cortex $\rightarrow$ Thalamus

b

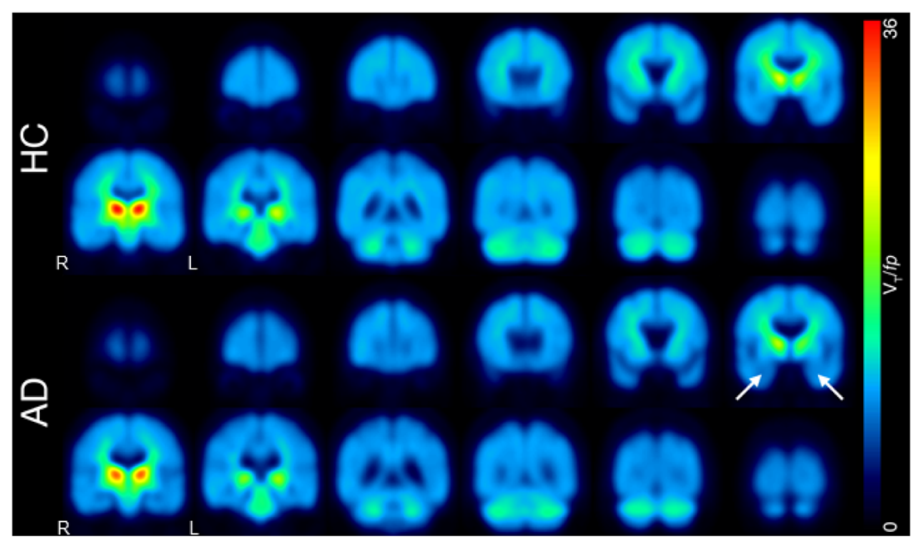


deviation increased by $24.4 \%$ (range $7.0-46.0 \%$ ) and approximately $45.0 \%$ (range $0.4-69.5 \%$ ), respectively. Mean PVEcorrected $(+)-\left[{ }^{18} \mathrm{~F}\right]$ Flubatine binding values $\left(V_{\mathrm{T}} / f \mathrm{p}_{\mathrm{PVEC}}\right)$ of the right mesial temporal cortex were $13.26 \pm 1.90$ in $\mathrm{HCs}$ and $12.45 \pm 1.08$ in $\mathrm{AD}$ patients $(p=0.13)$ and of the left mesial temporal cortex $13.74 \pm 2.07$ in HCs and $12.48 \pm 1.48$ in $\mathrm{AD}$ patients $(p=0.07)$. Figure 4 and Supplementary Figure 6 illustrate the effect of the PVE correction on the mean $V_{\mathrm{T}} / f_{\mathrm{p}}$ values and standard deviation.

\section{Cortical thickness and $(+)-\left[{ }^{18}\right.$ F]Flubatine PET data}

In 8 of 11 left-sided and 7 of 11 right-sided regions, the cortical thickness in the AD patients was significantly lower than in the HCs (Table 5). When correcting for age and gender, $(+)-\left[{ }^{18} \mathrm{~F}\right]$ Flubatine binding $\left(V_{\mathrm{T}} / f_{\mathrm{p}}\right)$ and cortical thickness were not correlated in the mesial temporal cortices: entire study population (left $r=0.18, p=0.48$; right $r=0.44, p=0.07$ ); HCs (left $r=-0.41, p=0.28$; right $r=0.42, p=0.92$ ); AD patients (left $r=0.64, p=0.12$; right $r=0.72, p=0.07$ ) nor in the left precuneus: entire study population $(r=0.23, p=$ $0.36)$; HCs $(r=0.1, p=0.81)$; AD $(r=0.11, p=0.82)$. Without covariates. a correlation between $(+)-\left[{ }^{18} \mathrm{~F}\right]$ Flubatine binding $\left(V_{\mathrm{T}} / f_{\mathrm{p}}\right)$ and cortical thickness were solely detectable in the left mesiotemporal cortex in the AD group (entire study population: left $r=0.29, p=0.22$; right $r=0.29, p=0.21$; HCs: left $r=-0.50, p=0.12$; right $r=0.26, p=0.44$; AD patients: left $r=0.74, p=0.02$; right $r=0.44, p=0.23$ ) and still no correlation was detectable in the left precuneus: entire study population $(r=0.38, p=0.10)$; HCs $(r=0.04, p=$ $0.91)$; AD patients $(r=0.65, p=0.06)$.

Table 3 Comparison of the regional (+)- $\left[{ }^{18} \mathrm{~F}\right]$ Flubatine binding between patients with mild Alzheimer's disease (ADs) and healthy controls (HCs)

\begin{tabular}{llll}
\hline Region & \multicolumn{2}{l}{$V_{\mathrm{T}} / f_{\mathrm{p}}$} & \multirow{2}{*}{$p$} \\
\cline { 2 - 3 } & $\mathrm{HCs}$ & $\mathrm{ADs}$ & \\
\hline Left frontal cortex & $11.8 \pm 1.7$ & $11.1 \pm 0.94$ & 0.134 \\
Left mesial temporal cortex & $12.2 \pm 1.8$ & $11.0 \pm 1.1$ & 0.046 \\
Left parietal cortex & $11.9 \pm 1.3$ & $11.5 \pm 1.0$ & 0.176 \\
Left anterior cingulate cortex & $13.0 \pm 1.9$ & $12.1 \pm 1.3$ & 0.113 \\
Left posterior cingulate cortex & $12.4 \pm 1.9$ & $12.1 \pm 1.1$ & 0.339 \\
Right frontal cortex & $11.8 \pm 1.8$ & $11.4 \pm 0.9$ & 0.247 \\
Right mesial temporal cortex & $11.6 \pm 1.4$ & $10.6 \pm 1.1$ & 0.049 \\
Right parietal cortex & $12.6 \pm 1.6$ & $11.7 \pm 1.3$ & 0.088 \\
Right anterior cingulate cortex & $12.9 \pm 1.9$ & $12.3 \pm 1.2$ & 0.188 \\
Right posterior cingulate cortex & $12.6 \pm 1.8$ & $12.1 \pm 1.4$ & 0.239 \\
\hline
\end{tabular}

(+)- $\left[{ }^{18} \mathrm{~F}\right]$ Flubatine binding is expressed as distribution volumes divided by the free fraction in plasma $(V T / f \mathrm{p})$. $V_{\mathrm{T}}$ estimated are from 0 - to 90 -min p.i. PET scans. Values are given as mean value \pm standard deviation
Neuropsychological testing and $(+)-\left[{ }^{18}\right.$ F]Flubatine PET data

The correlation analyses between $\mathrm{z}$ scores of the CERAD subtests $(n=11)$ and the regional $(n=16)(+)-\left[{ }^{18}\right.$ F]Flubatine binding $\left(V_{\mathrm{T}} / f_{\mathrm{p}}\right)$ did not reveal any significant correlations. In the entire study group performance in A-K-T-PR was significantly correlated with $V_{\mathrm{T}} / f_{\mathrm{p}}$ of the left anterior cingulate cortex $(r=0.504, p=0.028)$ and right posterior cingulate cortex $(r=0.540, p=0.017)$. Test data of WMS (immediate memory) were correlated with $V_{\mathrm{T}} / f_{\mathrm{p}}$ of the right parietal cortex $(r=$ $0.541, p=0.030$ ). No correlations were found between regional $V_{\mathrm{T}} / f_{\mathrm{p}}$ and test scores of DemTect or WMS (delayed memory). Graphs of the regression analysis are shown in Fig. 5.

Examining the $\mathrm{AD}$ group alone performance in A-K-T-PR was not statistically correlated with $V_{\mathrm{T}} / f_{\mathrm{p}}$ of the anterior or posterior cingulate cortices, but a trend could be stated (left ACC $r=0.621, p=0.074$; right ACC $r=0.619, p=0.075$; left $\mathrm{PCC} r=0.661, p=0.052$; right $\mathrm{PCC} r=0.650, p=0.058$ ); test scores of WMS (immediate memory) and $V_{\mathrm{T}} / f_{\mathrm{p}}$ of the right parietal cortex were not correlated $(r=0.567, p=0.112)$.

\section{$\left[{ }^{11} \mathrm{C}\right]$ PiB PET and $(+)-\left[{ }^{18} \mathrm{~F}\right]$ Flubatine binding}

The VOI-based analyses within the same region as well as across regions revealed significant correlations between $(+)-\left[{ }^{18} \mathrm{~F}\right]$ Flubatine binding and $\left[{ }^{11} \mathrm{C}\right] \mathrm{PiB}$ SUV ratios (reference region: cerebellar cortex) (Fig. 6). In the HCs, the white matter binding of $\left[{ }^{11} \mathrm{C}\right] \mathrm{PiB}$ was positively correlated with the $(+)-\left[{ }^{18} \mathrm{~F}\right]$ Flubatine binding in all cortical regions of interest (Fig. 6, Supplementary Figure 5). In the AD patients, (+)- $\left[{ }^{18} \mathrm{~F}\right]$ Flubatine binding of the lateral temporal cortex was negatively correlated with $\left[{ }^{11} \mathrm{C}\right] \mathrm{PiB}$ SUV ratios of the lateral temporal, parietal, and anterior cingulate cortex as well as the white matter (Fig. 6, Supplementary Figure 5).

\section{$(+)-\left[{ }^{18} \mathrm{~F}\right]$ Flubatine PET safety evaluation}

No serious adverse events occurred. None of the adverse events was related to the investigational product.

\section{Discussion}

We present data of the first-in-human brain imaging study of the new $\alpha 4 \beta 2$ nAChR-targeting PET ligand $(+)-\left[{ }^{18} \mathrm{~F}\right]$ Flubatine, the enantiomer of the recently introduced, highly $\alpha 4 \beta 2 \mathrm{nAChR}-$ specific $(-)-\left[{ }^{18} \mathrm{~F}\right]$ Flubatine [5]. Overall, we found that $(+)-\left[{ }^{18} \mathrm{~F}\right]$ Flubatine is a safe and stable radioligand with favorable characteristics. The correlation analysis between regional $V_{\mathrm{T}}$ values and injected mass in HCs did not show any significant correlation. However, in 
Table 4 Voxel-based analyses listing the regions/ clusters where patients with Alzheimer's disease had lower (+)-Flubatine binding compared with healthy controls

\begin{tabular}{llllll}
\hline Region & $k$ & $p_{\text {uncorr(cluster level) }}$ & $p_{\text {uncorr(peak level) }}$ & $Z$ & $x, y, z$ \\
\hline Left hippocampus & 297 & 0.083 & $<0.0005$ & 4.04 & $-18-10-18$ \\
Left precuneus & 238 & 0.117 & $<0.0005$ & 3.74 & $-12-4812$ \\
Left putamen & 297 & 0.083 & $<0.0005$ & 3.64 & -22220 \\
Left precuneus & 224 & 0.127 & $<0.0005$ & 3.50 & $-30-5010$ \\
Right orbitofrontal cortex anterior & 60 & 0.425 & $<0.0005$ & 3.72 & $2472-22$ \\
Right paracentral lobule & 31 & 0.576 & $<0.0005$ & 3.58 & $16-3048$ \\
Left anterior cingulate cortex & 71 & 0.384 & $<0.0005$ & 3.41 & -63616 \\
Left triangular frontal inferior gyrus & 40 & 0.520 & $<0.0005$ & 3.30 & -38384 \\
\hline
\end{tabular}

(+)-Flubatine binding is expressed as $V_{\mathrm{T}} / f_{\mathrm{p}} . k$ cluster size expressed in $2 \times 2 \times 2 \mathrm{~mm}$ voxels; $x, y, z$ location of the peak in the three-dimensional stereotactic coordinates. Significance at $p<0.001$ uncorrected (peak level), $k>10$ voxels. Gender was used as covariate two of the 10 a-priori defined regions, the $p$ values showed a trend towards significance. We assume that these two trends are spurious correlations as the receptor occupancy should be the same in all regions and therefore a violation of the tracer principle should be detectable by significantly correlations in the majority of the investigated brain regions. Furthermore, as mandatory in every subject, a safety factor of more than 1000 was ensured between the injected mass and the preclinical evaluated no observed effect level (NOEL) of $1.55 \mu \mathrm{g} / \mathrm{kg}$. The visual evaluation showed that the dynamic PET data could be accurately analyzed with both a $1 \mathrm{TCM}$ and a 2TCM. Both approaches determined comparable $V_{\mathrm{T}} / f_{\mathrm{p}}$ values for all investigated brain regions. As the 1TCM approach is the more robust and the far less complicated matter, we decided to use this approach for the further analyses although the Akaike information criterion showed lower values for the 2TCM in the majority of the HCs. The fact that the distribution volumes can be sufficiently estimated with a $1 \mathrm{TCM}$ could be an indication for a fast reversible binding of (+)-[ $\left[{ }^{18} \mathrm{~F}\right]$ Flubatine to $\alpha 4 \beta 2 \mathrm{nAChRs}$. As expected, the $V_{\mathrm{T}} / f_{\mathrm{p}}$ values of the homoepibatidine derivative $(+)-\left[{ }^{18} \mathrm{~F}\right]$ Flubatine increased with $\alpha 4 \beta 2$ nAChR density known from postmortem studies, especially $\left[{ }^{3} \mathrm{H}\right]$ epibatidine autoradiographic binding studies [32-34]. Thus, we found in accordance with these studies the highest $(+)-\left[{ }^{18} \mathrm{~F}\right]$ Flubatine uptake in thalamus [32-34]. White matter, putamen, caudatus, pons, and

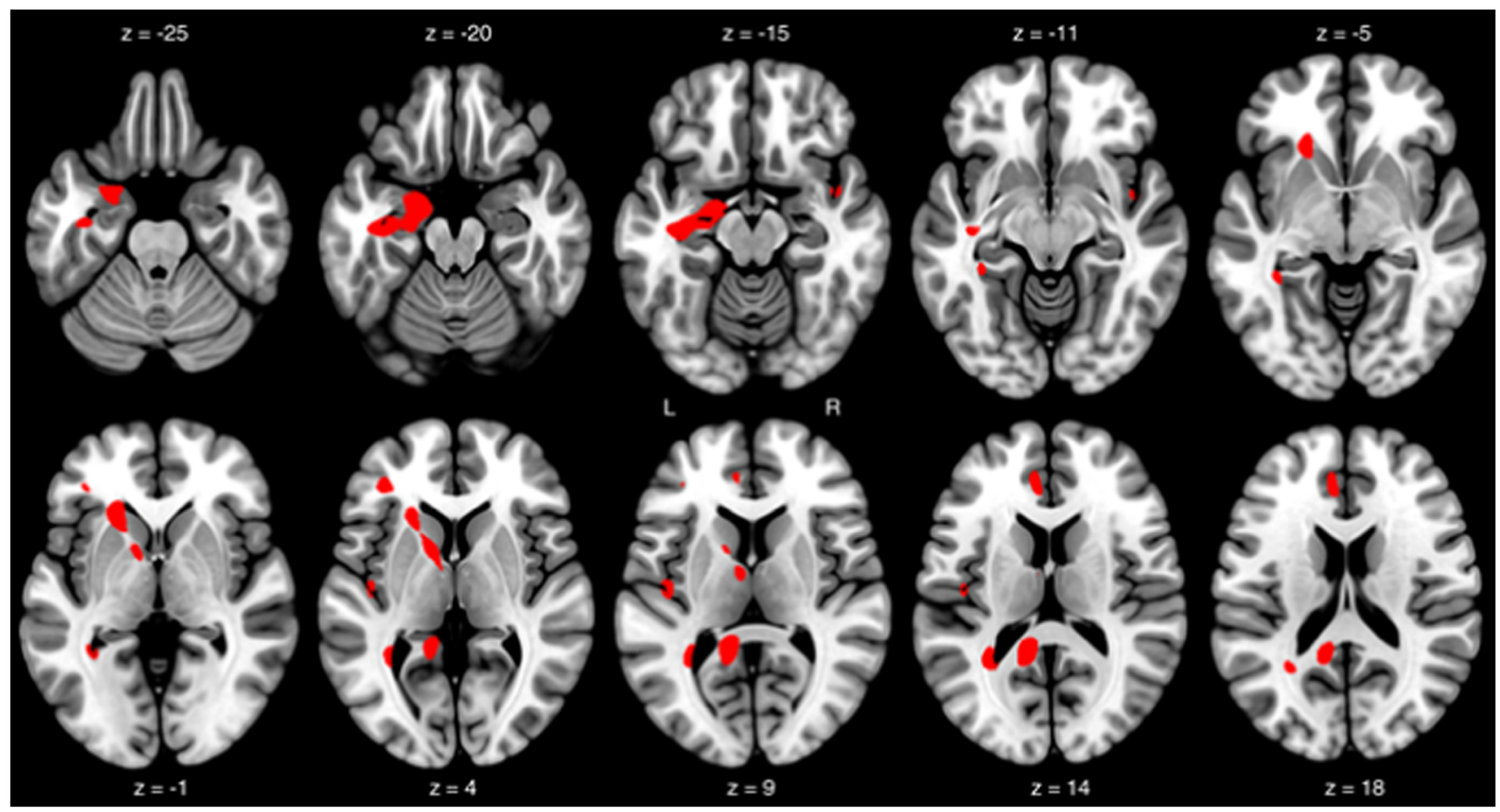

Fig. 3 Voxel-based (SPM) analyses demonstrating the regions/clusters where Alzheimer's disease (AD) patients had lower $(+)-\left[{ }^{18} \mathrm{~F}\right]$ Flubatine binding $\left(V_{\mathrm{T}} / f_{\mathrm{p}}\right)$ compared with healthy controls. $p<0.001$ uncorrected, $k>30$ voxels (covariable: gender) 

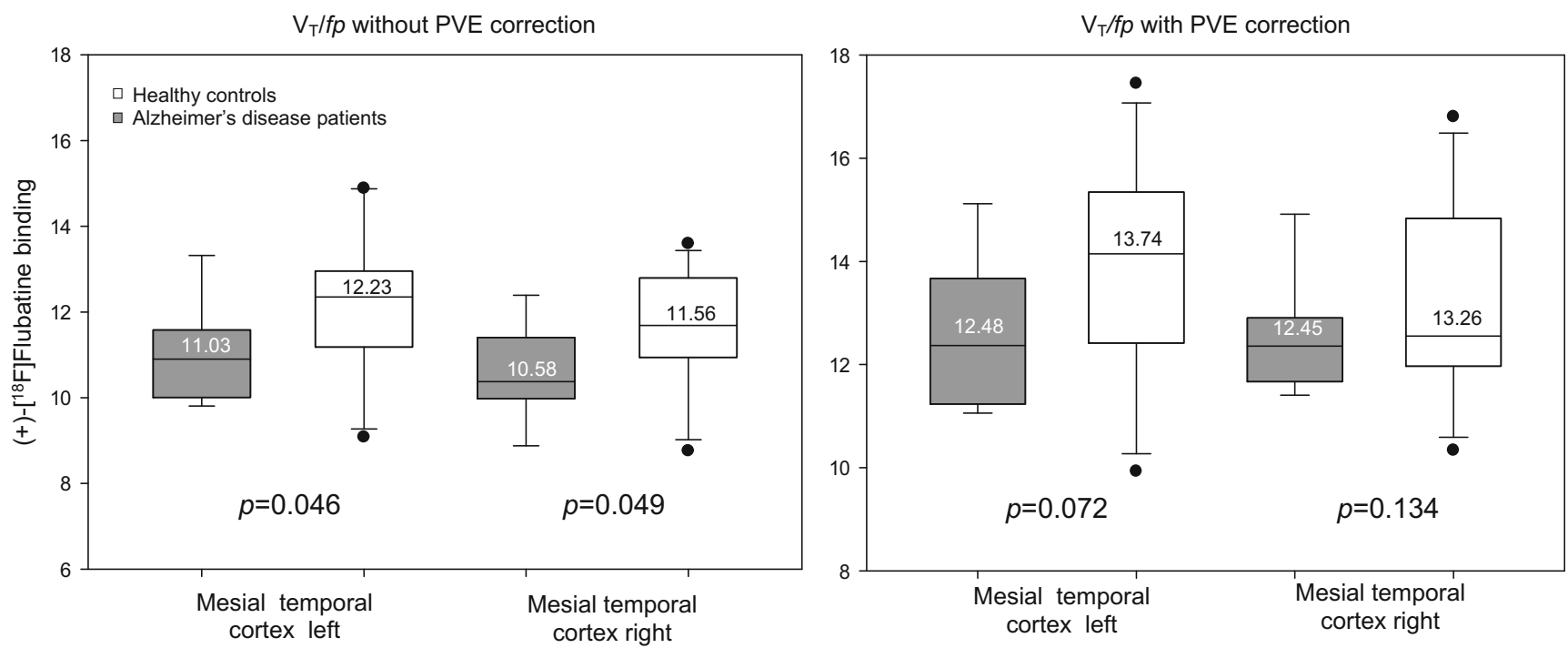

Fig. 4 Boxplots depicting the (+)-[ $\left.{ }^{18} \mathrm{~F}\right]$ Flubatine distribution volumes/ free fraction in plasma $\left(V_{\mathrm{T}} / f_{\mathrm{p}}\right)$ values in regions significantly different in the group analysis without partial volume effect (PVE) correction

substantia nigra showed an intermediate accumulation of $(+)-\left[{ }^{18} \mathrm{~F}\right]$ Flubatine and cortical regions had the lowest $V_{\mathrm{T}} / f_{\mathrm{p}}$ values. These results are also in line with different autoradiographic binding studies using $\left[{ }^{3} \mathrm{H}\right]$ epibatidine or $\left[{ }^{3} \mathrm{H}\right]$ nicotine to quantify nAChRs [32-36]. Furthermore, this regional distribution pattern was observed in several previous PET studies using other $\alpha 4 \beta 2 \mathrm{nAChRs}$ targeting radioligands [5, 10-12, 15, 37]. The tracer kinetics in HCs and patients were similar and a scan duration of 90 min was sufficient to estimate the distribution volumes in all cortical regions in HCs as well as AD patients. Thus, the kinetics of $(+)-\left[{ }^{18} \mathrm{~F}\right]$ Flubatine is faster than the kinetics of the early-generation $\alpha 4 \beta 2 \mathrm{nAChR}-$ targeting PET ligands like 2-[ $\left.{ }^{18} \mathrm{~F}\right] \mathrm{FA}-85380$ [13]. The kinetics of $(+)-\left[{ }^{18} \mathrm{~F}\right]$ Flubatine was moderately slower compared with

between the 9 patients with mild Alzheimer's disease (AD) and the 10 healthy controls (HCs) and the $V_{\mathrm{T}} / f_{\mathrm{p}}$ values of the same regions after PVE correction. Numbers in the boxplots state the mean values

that of the recently published $(-)-\left[{ }^{18} \mathrm{~F}\right]$ Flubatine, but faster than assumed by preclinical data [16]. In contrast to $(-)-\left[{ }^{18} \mathrm{~F}\right]$ Flubatine which showed a low number of metabolites $[5,8,9]$, metabolic degradation of $(+)-\left[{ }^{18} \mathrm{~F}\right]$ Flubatine was negligible. Therefore, a metabolite correction for $(+)-\left[{ }^{18} \mathrm{~F}\right]$ Flubatine is not required at all. We compared $(+)-\left[{ }^{18} \mathrm{~F}\right]$ Flubatine binding in 9 patients with mild to moderate $\mathrm{AD}$ with that in 11 healthy controls. Using voxel-based analysis, we obtained significantly reduced $\alpha 4 \beta 2 \mathrm{nAChR}$ availability in the bilateral mesial temporal cortex, in the left precuneus, left putamen, and in smaller clusters also in the bilateral frontal cortex and the left anterior cingulate cortex in $\mathrm{AD}$ patients. In other regions, $(+)-\left[{ }^{18} \mathrm{~F}\right]$ Flubatine binding differences between $\mathrm{AD}$ patients and $\mathrm{HCs}$ did not reach

Table 5 Regional cortical thickness in patients with mild Alzheimer's disease (AD) and healthy controls (HCs)

\begin{tabular}{|c|c|c|c|c|c|c|}
\hline \multirow[t]{2}{*}{ Region } & \multicolumn{3}{|c|}{ Left hemisphere } & \multicolumn{3}{|c|}{ Right hemisphere } \\
\hline & $\mathrm{HCs}$ & ADs & $p$ & $\mathrm{HCs}$ & ADs & $p$ \\
\hline Caudal anterior cingulate & $2.81 \pm 0.28$ & $2.56 \pm 0.38$ & 0.115 & $2.49 \pm 0.34$ & $2.41 \pm 0.27$ & 0.576 \\
\hline Entorhinal & $3.37 \pm 0.35$ & $2.75 \pm 0.66$ & 0.016 & $3.52 \pm 0.37$ & $2.97 \pm 0.59$ & 0.020 \\
\hline Fusiform & $2.60 \pm 0.12$ & $2.34 \pm 0.25$ & 0.006 & $2.63 \pm 0.14$ & $2.24 \pm 0.29$ & 0.001 \\
\hline Inferior temporal & $2.68 \pm 0.17$ & $2.46 \pm 0.21$ & 0.019 & $2.75 \pm 0.12$ & $2.53 \pm 0.21$ & 0.010 \\
\hline Isthmus cingulate & $2.32 \pm 0.21$ & $2.06 \pm 0.29$ & 0.033 & $2.32 \pm 0.23$ & $1.90 \pm 0.29$ & 0.002 \\
\hline Medial orbitofrontal & $2.28 \pm 0.14$ & $2.07 \pm 0.22$ & 0.014 & $2.27 \pm 0.20$ & $2.12 \pm 0.19$ & 0.111 \\
\hline Parahippocampal & $2.71 \pm 0.29$ & $2.44 \pm 0.44$ & 0.126 & $2.57 \pm 0.21$ & $2.31 \pm 0.36$ & 0.062 \\
\hline Posterior cingulate & $2.47 \pm 0.16$ & $2.16 \pm 0.35$ & 0.017 & $2.43 \pm 0.16$ & $2.14 \pm 0.35$ & 0.027 \\
\hline Precuneus & $2.18 \pm 0.18$ & $1.91 \pm 0.29$ & 0.021 & $2.18 \pm 0.14$ & $1.94 \pm 0.28$ & 0.020 \\
\hline Superior frontal & $2.61 \pm 0.11$ & $2.32 \pm 0.29$ & 0.007 & $2.58 \pm 0.16$ & $2.33 \pm 0.25$ & 0.015 \\
\hline Superior parietal & $2.05 \pm 0.13$ & $1.89 \pm 0.23$ & 0.059 & $2.00 \pm 0.10$ & $1.87 \pm 0.19$ & 0.058 \\
\hline
\end{tabular}

Values are $\mathrm{mm}$, given as mean value \pm standard deviation 
Fig. 5 Graphs of the regression analyses showing a a significant linear regression between scores of the Alters-Konzentrations-Test (A-K-T) and (+)- $\left[{ }^{18}\right.$ F]Flubatine binding $\left(V_{\mathrm{T}} / f_{\mathrm{p}}\right)$ of the left anterior cingulate cortex, $\mathbf{b}$ a significant linear regression between scores of the Alters-Konzentrations-Test (A-K-T) and (+)- $\left[{ }^{18}\right.$ F $]$ Flubatine binding $\left(V_{\mathrm{T}} / f_{\mathrm{p}}\right)$ of the right posterior cingulate cortex, and $\mathbf{c}$ a significant linear regression between scores of the Wechsler memory scale and $(+)-\left[{ }^{18} \mathrm{~F}\right]$ Flubatine binding $\left(V_{\mathrm{T}} / f_{\mathrm{p}}\right)$ of the right parietal cortex

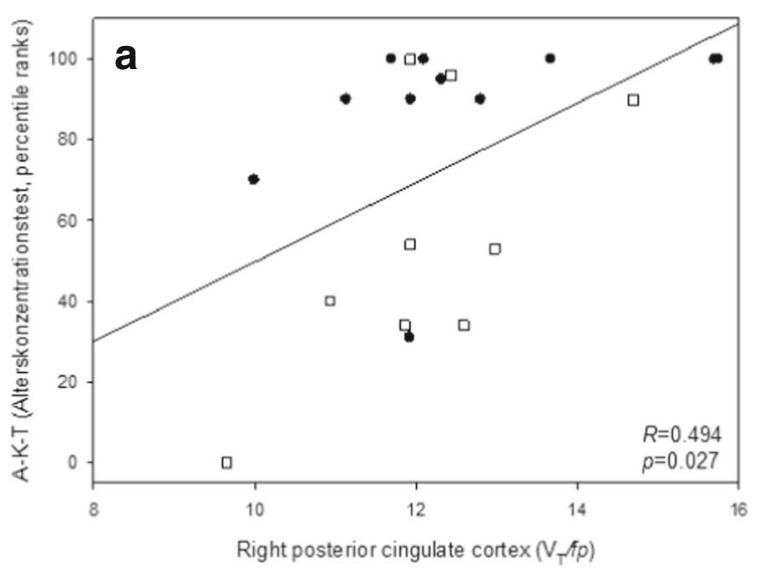

Subgroups:

- Healthy controls AD patients
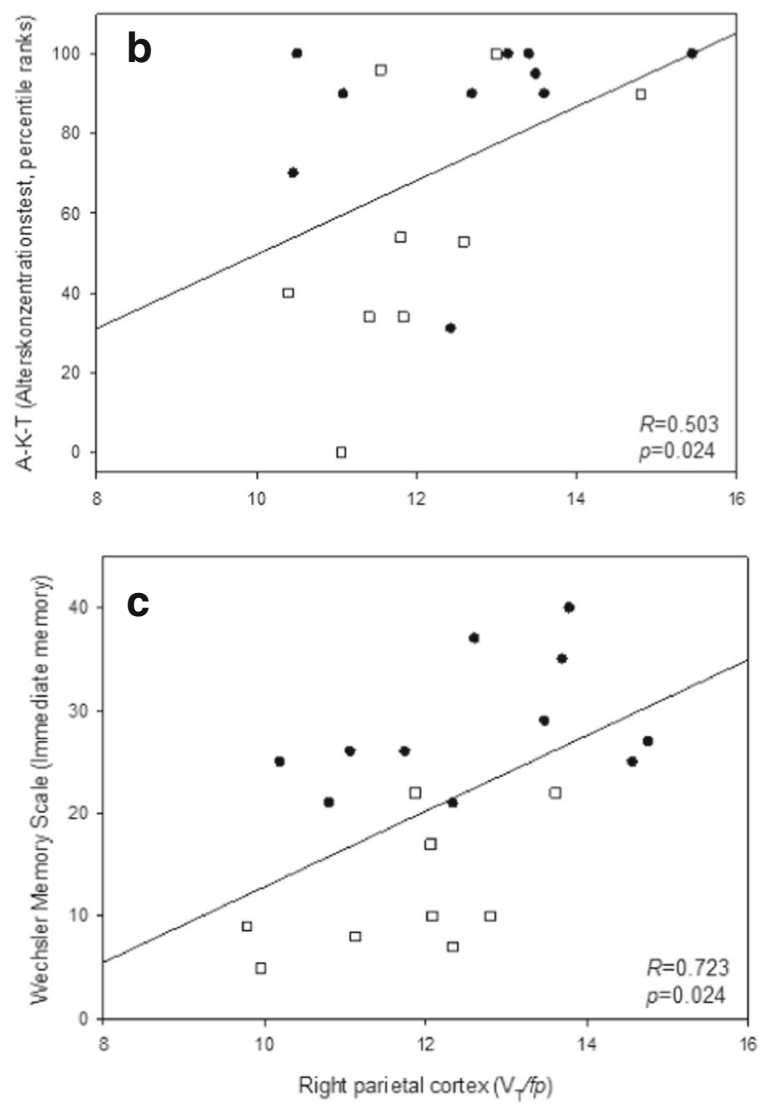

significance, potentially because of the inter-individual variability of the $\alpha 4 \beta 2 \mathrm{nAChR}$ availability. To minimize this variability in evaluating PET and SPECT images, the implementation of a reference region is typical. In former studies, we used the corpus callosum as reference region $[5,9,10,13]$. However, this region is difficult to delineate and in a recently published study, $(-)-\left[{ }^{18} \mathrm{~F}\right]$ Flubatine was displaceable by $21 \pm$ $9 \%$ in the corpus callosum in smokers [38], indicating that at least in smokers, a relevant specific binding is available in this region which is known as the region with the lowest amount of $\alpha 4 \beta 2 \mathrm{nAChRs}$ in humans. Thus, the corpus callosum does not seem to be very suitable as reference region for
(+)- $\left[{ }^{18} \mathrm{~F}\right]$ Flubatine. As $\alpha 4 \beta 2 \mathrm{nAChRs}$ are ubiquitous in the human brain, an optimal reference region without receptor binding does not exist. Our regions of interest are gray matter regions. Therefore, the reference region should also consist of gray matter and should be large enough to be easily delineated. Thus, we determined the occipital cortices as most suitable reference region considering that this region is only affected in severe stages of $\mathrm{AD}$ [39]. The evaluation with this reference region showed relatively reduced availability of $\alpha 4 \beta 2$ nAChRs in the AD patients compared with HCs in the afore-noted mesial temporal cortices, and further in the right parietal cortex. A tendency in the same direction was also 
Fig. 6 Matrices showing Pearson correlations between (+)- $\left[{ }^{18} \mathrm{~F}\right]$ Flubatine binding $\left(\mathrm{V}_{\mathrm{T}} /\right.$ $f p)$ and $\left[{ }^{11} \mathrm{C}\right] \mathrm{PiB}$ accumulation (standardized uptake value ratio (SUVRs), reference region: cerebellar cortex) across regions for the Alzheimer's disease (AD) patients and healthy controls. Asterisks indicate significant correlations $(p<0.05)$

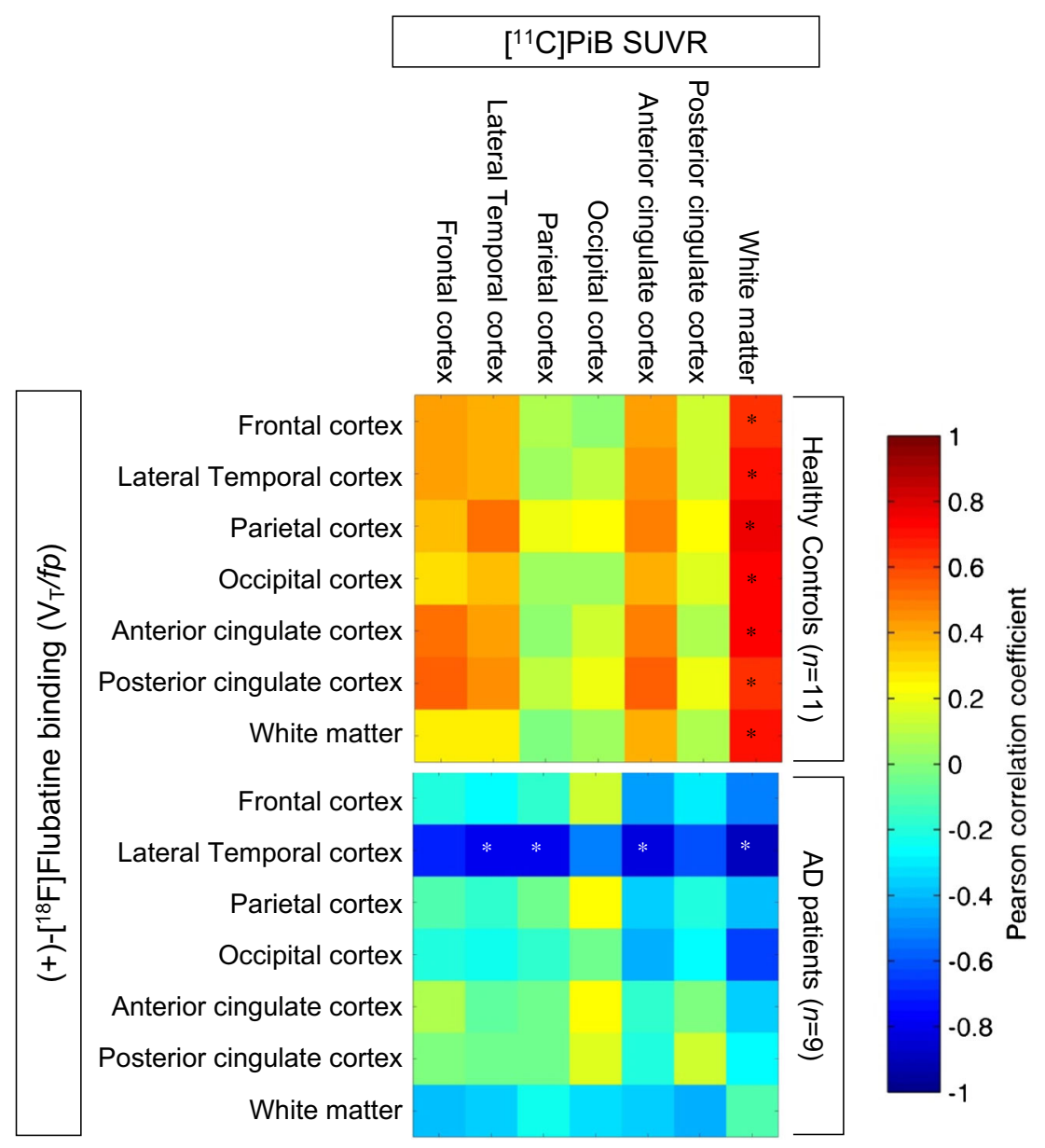

detected in the left frontal cortex. As all 10 candidate regions of interest were considered to be of substantive interest, apriori (based on our results from earlier PET studies of nicotine receptors in $\mathrm{AD}$ patients with early-generation radiotracers $[9,10,13])$ no multiplicity adjustment was incorporated. However, the significances would not survive a correction due to multiple testing. Autoradiographic binding studies consistently found reduced binding sites in temporal and frontal cortices in patients with Alzheimer's disease/dementia with reductions of approximately 50-60\%, especially in the temporal cortices [19, 36, 40-46]. Furthermore, several studies using 2-[ $\left.{ }^{18} \mathrm{~F}\right]$ fluoro-A-85380 as PET ligand revealed similar reduction patterns with reduced $\alpha 4 \beta 2 \mathrm{nAChRs}$ in the frontal, temporal, and anterior cingulate and posterior cingulate cortices as well as in subcortical regions (i.e., caudate, thalamus) $[4,9,10,12,13,15]$. In the current study, the extent of the $\alpha 4 \beta 2 \mathrm{nAChR}$ reduction is comparatively small. The mild manifestation of the AD (mean MMSE score 25) might explain these results. Applying partial volume effect correction increased the detected values of $(+)-\left[{ }^{18} \mathrm{~F}\right]$ Flubatine binding $\left(V_{\mathrm{T}} / f_{\mathrm{p}}\right)$ by approximately $15 \%$. The relation between the mean values of the $\mathrm{HC}$ and $\mathrm{AD}$ group remained unchanged. However, the standard deviation was also increased but by a larger and more inhomogeneous amount (0.4-70\%). We observed very similar results using PVE correction in another recently published study of the enantiomer $(-)-\left[{ }^{18} \mathrm{~F}\right]$ Flubatine [9]. Our data indicate that PVE correction might correct the binding values but simultaneously increases the variance and thus the statistical noise which itself impairs the group statistics, especially in small study cohorts, and results in loss of statistical significance. Hence, we used a second approach, i.e., measuring the cortical thickness to investigate whether cortical atrophy is the reason for reduced regional (+)- $\left[{ }^{18}\right.$ F]Flubatine binding in AD. Quantitatively, the cortical thickness in the AD patients, compared with healthy controls, was not only lower in the mesial temporal cortex and adjoining areas but also in most of the examined cortical regions. As expected [47], the bilateral entorhinal cortices and the isthmus of the left cingulate cortex showed the most severe atrophy with approximately 15-18\% reduction in AD patients compared with HCs. To investigate whether cortical atrophy and $(+)-\left[{ }^{18}\right.$ F]Flubatine binding were associated, we correlated the values of the mesial temporal cortices and the left precuneus where the largest clusters of lower $(+)-\left[{ }^{18}\right.$ F $]$ Flubatine binding were located. These data were not correlated using age and gender as covariates. Without covariates, we revealed a 
correlation between $(+)-\left[{ }^{18} \mathrm{~F}\right]$ Flubatine binding and cortical thickness solely in the left mesiotemporal in the AD patient. Therefore, we assume that the different $\alpha 4 \beta 2$ nAChR availability between $\mathrm{AD}$ patients and HCs in the left precuneus and in the right mesiotemporal cortex was not significantly affected by cortical atrophy. However, the different $4 \beta 2$ nAChR availability in the left mesiotemporal cortex might partially be caused by cortical atrophy in the AD patients. Furthermore, we found a reduced influx and washout constant in the bilateral mesial temporal cortices in the AD patients. The estimation of regional $V_{\mathrm{T}}$ values by correct kinetic modeling is independent of perfusion differences between the study groups and therefore (+)- $\left[{ }^{18} \mathrm{~F}\right]$ Flubatine $V_{\mathrm{T}}$ values reflect the availability of $\alpha 4 \beta 2 \mathrm{nAChR}$ alone. However, it cannot be completely ruled out that the observed reduction of uncorrected mesiotemporal (+)- $\left[{ }^{18} \mathrm{~F}\right]$ Flubatine binding in the $\mathrm{AD}$ patients was driven by atrophy. The thorough neuropsychological testing revealed only three correlations between neurocognitive test data and $(+)-\left[{ }^{18} \mathrm{~F}\right]$ Flubatine binding. This might be a result of the small number of patients who were, further, only mildly impaired (four patients had an MMSE score of 26 and further four of 24 or 25). The scores of the Alters-Konzentrations-Test (A-K-T) were correlated to the $\alpha 4 \beta 2$ nAChR availability in the left ACC and right PCC and immediate memory scores (WMS) to the right parietal cortex. In other study populations with moderately impaired $\mathrm{AD}$, patients cognitive test data and $\alpha 4 \beta 2 \mathrm{nAChR}$ availability were significantly correlated in several cortical regions especially regions that are typically affected in $\mathrm{AD}$ (i.e., frontal, temporal, parietal, and cingulate cortices) $[9,10,13,48]$.

As a screening procedure, all subjects underwent a $\beta$ amyloid simultaneous PET/MRI examination. Thus, we were able to also investigate the association between regional availability of $\alpha 4 \beta 2 \mathrm{nAChR}$ and $\beta$-amyloid accumulation. Okada et al. [12] correlated $\left[{ }^{11} \mathrm{C}\right] \mathrm{PiB}$ (nondisplaceable binding potential- $\mathrm{BP}_{\mathrm{ND}}$ ) determined in 5 -mm VOIs in the medial prefrontal cortices to $2-\left[{ }^{18} \mathrm{~F}\right] \mathrm{FA}-85380\left(\mathrm{BP}_{\mathrm{RI}}\right)$ of nine regions defined by a MRI atlas and found a negative correlation between $\left[{ }^{11} \mathrm{C}\right] \mathrm{PiB}\left(\mathrm{BP}_{\mathrm{ND}}\right)$ of the medial prefrontal VOI and $2-\left[{ }^{18} \mathrm{~F}\right] \mathrm{FA}-85380\left(\mathrm{BP}_{\mathrm{RI}}\right)$ in the medial frontal cortex and nucleus basalis of Meynert. In contrast to Okada et al. [12], we used manually drawn VOIs and used those to determine and correlate the $\left[{ }^{11} \mathrm{C}\right] \mathrm{PiB}$ and $(+)-\left[{ }^{18} \mathrm{~F}\right]$ Flubatine binding. In our $\mathrm{HC}$ group, we obtained a positive correlation between $\left[{ }^{11} \mathrm{C}\right] \mathrm{PiB}$ binding in the white matter and $\alpha 4 \beta 2 \mathrm{nAChR}$ availability of all investigated cortical regions. It has been demonstrated that $\left[{ }^{11} \mathrm{C}\right] \mathrm{PiB}$ binding in the white matter is associated with myelin sheaths [31]. A higher density of myelin sheathed fibers should be associated with a higher density of neurons, receptors, and transporters which would result in a higher (+) $\left[{ }^{18} \mathrm{~F}\right]$ Flubatine binding. Another explanation for the positive correlation could be an indirect association between axonal transport in white matter and receptor availability. In $\mathrm{AD}$ patients, this positive correlation between white matter binding of $\left[{ }^{11} \mathrm{C}\right] \mathrm{PiB}$ and $\alpha 4 \beta 2 \mathrm{nAChR}$ availability measured by $(+)-\left[{ }^{18} \mathrm{~F}\right]$ Flubatine binding was not detected. This might be an expression of infirmity and/or impairment of these processes. Instead, we found a negative correlation between $(+)-\left[{ }^{18} \mathrm{~F}\right]$ Flubatine binding of the lateral temporal cortex and $\left[{ }^{11} \mathrm{C}\right] \mathrm{PiB}$ accumulation of several cortical regions (i.e., lateral temporal, parietal, and anterior cingulate cortex as well as white matter) in the AD patients. However, we did not find a correlation in the frontal region as published by Okada et al. [12]. Different analysis approaches (voxel vs. region based), radioligands $\left(2-\left[{ }^{18} \mathrm{~F}\right] \mathrm{FA}-85380\left(\mathrm{BP}_{\mathrm{RI}}\right)\right.$ vs. $(+)-\left[{ }^{18} \mathrm{~F}\right]$ Flubatine $\left(V_{\mathrm{T}} / f_{\mathrm{p}}\right)$ ), and modeling (e.g., with or without using a reference region) as well as study populations (20 moderate vs. 9 mild $\mathrm{AD}$ patients) might be explanations for the different results. The lateral temporal cortex receives its cholinergic fibers from the lateral pathway that travels ventrally from the nucleus basalis of Meynert directly in the temporal regions [49]. $\beta$ Amyloid deposits located in the lateral temporal cortex might impair these fibers which could explain the observed negative correlation between $\alpha 4 \beta 2 \mathrm{nAChR}$ availability and $\beta$-amyloid deposits in this region. However, a direct impairment of these fibers by $\beta$-amyloid deposits in the parietal or anterior cingulate cortex is unlikely. These negative correlations could be based on an indirect association. Examinations in larger study cohorts are necessary to verify these interesting results.

Overall, (+)-[ $\left.{ }^{18} \mathrm{~F}\right]$ Flubatine as $\alpha 4 \beta 2 \mathrm{nAChR}$-targeting PET radiotracer has the potential to be applied in further clinical trials examining neurological or psychiatric diseases like dementia, parkinsonian syndromes, or depression. Naturally, tobacco smoke or central acting medication with effect on $\alpha 4 \beta 2$ nAChR interferes with the cerebral accumulation of (+)- $\left[{ }^{18} \mathrm{~F}\right]$ Flubatine like every other $\alpha 4 \beta 2 \mathrm{nAChR}$-targeting radiotracer. The sufficient scan duration of $90 \mathrm{~min}$ is a substantial progress in comparison with the early-generation $\alpha 4 \beta 2$ nAChR-targeting PET ligands like 2-[ $\left.{ }^{18} \mathrm{~F}\right] \mathrm{FA}-85380$. However, full kinetic modeling is still required until follow-up studies prove a simplified method as applicable. As noted already, a limitation of this study is the small sample size. The mild manifestation of $\mathrm{AD}$ in our patients was necessary to investigate whether reduced $\alpha 4 \beta 2 \mathrm{nAChR}$ availability is already detectable in this early clinical stage of disease. However, results of secondary aims, e.g., correlation between $\alpha 4 \beta 2 \mathrm{nAChR}$ availability and cognitive test data, might be less distinctive because of the coincidence of small sample size and mild manifestation of AD.

\section{Conclusion}

$(+)-\left[{ }^{18} \mathrm{~F}\right]$ Flubatine is a safe and stable PET ligand. The $\alpha 4 \beta 2$ nAChR availability can be quantified using $(+)-\left[{ }^{18} \mathrm{~F}\right]$ Flubatine PET by a 1TCM. The amount of metabolites is negligible 
and therefore no metabolite correction needs to be applied to the arterial input function. A scan duration of $90 \mathrm{~min}$ is sufficient to analyze all cortical regions. The high (+)- $\left[{ }^{18} \mathrm{~F}\right]$ Flubatine binding in subcortical structures is favorable. In comparison with $\mathrm{HCs}$, patients with mild to moderate $\mathrm{AD}$ showed a reduced availability of $\alpha 4 \beta 2 \mathrm{nAChRs}$ in the bilateral mesial temporal cortex. Here, $(+)-\left[{ }^{18} \mathrm{~F}\right]$ Flubatine binding affinity was high enough to distinguish groups without using a reference region. However, the use of a reference region increased the sensitivity. Of interest, correlation between white matter $\beta$-amyloid PET uptake and $(+)-\left[{ }^{18} \mathrm{~F}\right]$ Flubatine binding indicates an association between white matter integrity and availability of $\alpha 4 \beta 2 \mathrm{nAChRs}$. Overall, $(+)-\left[{ }^{18} \mathrm{~F}\right]$ Flubatine has the potential to serve as $\alpha 4 \beta 2$-targeting PET ligand in humans.

Acknowledgments We would like to thank all $\mathrm{AD}$ patients, their relatives, and the healthy subjects for taking part in this trial.

Authors' contributions All authors contributed to the study conception and design. Material preparation, data collection, and analysis were performed by Solveig Tiepolt, Georg-Alexander Becker, Stephan Wilke, Diego Cecchin, Michael Rullmann, Philipp M. Meyer, Henryk Barthel, Swen Hesse, Marianne Patt, Julia Luthardt, Herrmann-Josef Gertz, Peter Brust, and Osama Sabri. The first draft of the manuscript was written by Solveig Tiepolt and all authors commented on the previous version of the manuscript. All authors read an approved the final manuscript.

Funding Open Access funding enabled and organized by Projekt DEAL. This study was financially supported by the Helmholtz-Society (Helmholtz validation fond, HVF-0012 "NikotinPET"). The funding source had no involvement in the collection, analysis and interpretation of the data.

\section{Compliance with ethical standards}

Conflict of interest Dr. Hoepping and Dr. Smits are employees of ABX advanced biochemical compounds. The other authors have no disclosures related to the study.

Ethics approval The study was conducted according to the 1964 Helsinki declaration and subsequent revisions. It was approved by the ethical committee at the medical faculty of Leipzig University as well as the Federal Office for Radiation Protection and the Federal Institute for Drugs and Medical Devices of Germany (Eudra-CT no. 2012-00347326). Safety and tolerability was documented according to the standard of good-clinical-practice. All subjects gave written informed consent.

Open Access This article is licensed under a Creative Commons Attribution 4.0 International License, which permits use, sharing, adaptation, distribution and reproduction in any medium or format, as long as you give appropriate credit to the original author(s) and the source, provide a link to the Creative Commons licence, and indicate if changes were made. The images or other third party material in this article are included in the article's Creative Commons licence, unless indicated otherwise in a credit line to the material. If material is not included in the article's Creative Commons licence and your intended use is not permitted by statutory regulation or exceeds the permitted use, you will need to obtain permission directly from the copyright holder. To view a copy of this licence, visit http://creativecommons.org/licenses/by/4.0/.

\section{References}

1. Jasinska AJ, Zorick T, Brody AL, Stein EA. Dual role of nicotine in addiction and cognition: a review of neuroimaging studies in humans [eng]. Neuropharmacology. 2014. https://doi.org/10. 1016/j.neuropharm.2013.02.015.

2. Nordberg A, Hartvig P, Lilja A, Viitanen M, Amberla K, Lundqvist $\mathrm{H}$, et al. Decreased uptake and binding of 11C-nicotine in brain of Alzheimer patients as visualized by positron emission tomography [eng]. J Neural Transm Park Dis Dement Sect. 1990;2(3):215-24.

3. Nybäck H, Halldin C, Ahlin A, Curvall M, Eriksson L. PET studies of the uptake of (S)- and (R)-11Cnicotine in the human brain: difficulties in visualizing specific receptor binding in vivo [eng]. Psychopharmacology. 1994;115(1-2):31-6.

4. Meyer PM, Tiepolt S, Barthel H, Hesse S, Sabri O. Radioligand imaging of $\alpha 4 \beta 2 *$ nicotinic acetylcholine receptors in Alzheimer's disease and Parkinson's disease [eng]. Q J Nucl Med Mol Imaging. 2014;58(4):376-86.

5. Sabri O, Becker GA, Meyer PM, Hesse S, Wilke S, Graef S, et al. First-in-human PET quantification study of cerebral alpha4beta2* nicotinic acetylcholine receptors using the novel specific radioligand (-)-(18)FFlubatine [eng]. Neuroimage. 2015. https:// doi.org/10.1016/j.neuroimage.2015.05.065.

6. Sattler B, Kranz M, Starke A, Wilke S, Donat CK, Deuther-Conrad W, et al. Internal dose assessment of (-)-18F-flubatine, comparing animal model datasets of mice and piglets with first-in-human results [eng]. J Nucl Med. 2014. https://doi.org/10.2967/jnumed.114.137059.

7. Wong DF, Kuwabara H, Kim J, Brasic JR, Chamroonrat W, Gao Y, et al. PET imaging of high-affinity $\alpha 4 \beta 2$ nicotinic acetylcholine receptors in humans with $18 \mathrm{~F}-\mathrm{AZAN}$, a radioligand with optimal brain kinetics [eng]. J Nucl Med. 2013. https://doi.org/10.2967/ jnumed.112.108001.

8. Patt M, Becker GA, Grossmann U, Habermann B, Schildan A, Wilke S, et al. Evaluation of metabolism, plasma protein binding and other biological parameters after administration of (-)-[(18)F]Flubatine in humans [eng]. Nucl Med Biol. 2014. https://doi.org/10.1016/j.nucmedbio.2014.03.018.

9. Sabri O, Meyer PM, Gräf S, Hesse S, Wilke S, Becker G-A, et al. Cognitive correlates of $\alpha 4 \beta 2$ nicotinic acetylcholine receptors in mild Alzheimer's dementia [eng]. Brain. 2018. https://doi.org/10. 1093/brain/awy099.

10. Kendziorra K, Wolf H, Meyer PM, Barthel H, Hesse S, Becker GA, et al. Decreased cerebral $\alpha 4 \beta 2 *$ nicotinic acetylcholine receptor availability in patients with mild cognitive impairment and Alzheimer's disease assessed with positron emission tomography [eng]. Eur J Nucl Med Mol Imaging. 2011. https://doi.org/10.1007/ s00259-010-1644-5.

11. O’Brien JT, Colloby SJ, Pakrasi S, Perry EK, Pimlott SL, Wyper DJ, et al. Alpha4beta2 nicotinic receptor status in Alzheimer's disease using 123I-5IA-85380 single-photon-emission computed tomography [eng]. J Neurol Neurosurg Psychiatry. 2007. https://doi. org/10.1136/jnnp.2006.108209.

12. Okada H, Ouchi Y, Ogawa M, Futatsubashi M, Saito Y, Yoshikawa $\mathrm{E}$, et al. Alterations in $\alpha 4 \beta 2$ nicotinic receptors in cognitive decline in Alzheimer's aetiopathology [eng]. Brain. 2013. https://doi.org/ 10.1093/brain/awt195.

13. Sabri O, Kendziorra K, Wolf H, Gertz H-J, Brust P. Acetylcholine receptors in dementia and mild cognitive impairment [eng]. Eur J Nucl Med Mol Imaging. 2008. https://doi.org/10.1007/s00259007-0701-1.

14. Terrière E, Dempsey MF, Herrmann LL, Tierney KM, Lonie JA, O'Carroll RE, et al. 5-(123)I-A-85380 binding to the $\alpha 4 \beta 2$-nicotinic receptor in mild cognitive impairment [eng]. Neurobiol Aging. 2010. https://doi.org/10.1016/j.neurobiolaging.2008.10.008. 
15. Sultzer DL, Melrose RJ, Riskin-Jones H, Narvaez TA, Veliz J, Ando TK, et al. Cholinergic receptor binding in Alzheimer disease and healthy aging: assessment in vivo with positron emission tomography imaging [eng]. Am J Geriatr Psychiatry. 2017. https:// doi.org/10.1016/j.jagp.2016.11.011.

16. Brust P, Patt JT, Deuther-Conrad W, Becker G, Patt M, Schildan A, et al. In vivo measurement of nicotinic acetylcholine receptors with [18F]norchloro-fluoro-homoepibatidine [eng]. Synapse. 2008. https://doi.org/10.1002/syn.20480.

17. Ludwig F-A, Fischer S, Smits R, Deuther-Conrad W, Hoepping A, Tiepolt $\mathrm{S}$, et al. Exploring the metabolism of (+)-18FFlubatine in vitro and in vivo: LC-MS/MS aided identification of Radiometabolites in a clinical PET study [eng]. Molecules. 2018. https://doi.org/10.3390/molecules23020464.

18. Perry E, Martin-Ruiz C, Lee M, Griffiths M, Johnson M, Piggott M, et al. Nicotinic receptor subtypes in human brain ageing, Alzheimer and Lewy body diseases [eng]. Eur J Pharmacol. 2000;393(1-3):215-22.

19. Perry EK, Martin-Ruiz CM, Court JA. Nicotinic receptor subtypes in human brain related to aging and dementia [eng]. Alcohol. 2001;24(2):63-8.

20. Clark CM, Pontecorvo MJ, Beach TG, Bedell BJ, Coleman RE, Doraiswamy PM, et al. Cerebral PET with florbetapir compared with neuropathology at autopsy for detection of neuritic amyloid$\beta$ plaques: a prospective cohort study [eng]. Lancet Neurol. 2012. https://doi.org/10.1016/S1474-4422(12)70142-4.

21. Sabri O, Sabbagh MN, Seibyl J, Barthel H, Akatsu H, Ouchi Y, et al. Florbetaben PET imaging to detect amyloid beta plaques in Alzheimer's disease: phase 3 study [eng]. Alzheimers Dement. 2015. https://doi.org/10.1016/j.jalz.2015.02.004.

22. Curtis C, Gamez JE, Singh U, Sadowsky CH, Villena T, Sabbagh $\mathrm{MN}$, et al. Phase 3 trial of flutemetamol labeled with radioactive fluorine 18 imaging and neuritic plaque density [eng]. JAMA Neurol. 2015. https://doi.org/10.1001/jamaneurol.2014.4144.

23. Scheltens P, Leys D, Barkhof F, Huglo D, Weinstein HC, Vermersch P, et al. Atrophy of medial temporal lobes on MRI in "probable" Alzheimer's disease and normal ageing: diagnostic value and neuropsychological correlates [eng]. J Neurol Neurosurg Psychiatry. 1992;55(10):967-72.

24. Burnham KP, Anderson DR. Model selection and multimodel inference. Springer New York: New York, NY; 2004.

25. Turkheimer FE, Hinz R, Cunningham VJ. On the undecidability among kinetic models: from model selection to model averaging [eng]. J Cereb Blood Flow Metab. 2003. https://doi.org/10.1097/ 01.WCB.0000050065.57184.BB.

26. Innis RB, Cunningham VJ, Delforge J, Fujita M, Gjedde A, Gunn $\mathrm{RN}$, et al. Consensus nomenclature for in vivo imaging of reversibly binding radioligands [eng]. J Cereb Blood Flow Metab. 2007. https://doi.org/10.1038/sj.jcbfm.9600493.

27. Desikan RS, Ségonne F, Fischl B, Quinn BT, Dickerson BC, Blacker D, et al. An automated labeling system for subdividing the human cerebral cortex on MRI scans into gyral based regions of interest [eng]. Neuroimage. 2006. https://doi.org/10.1016/j. neuroimage.2006.01.021.

28. Fischl B, Dale AM. Measuring the thickness of the human cerebral cortex from magnetic resonance images [eng]. Proc Natl Acad Sci U S A. 2000. https://doi.org/10.1073/pnas.200033797.

29. Bortz J. Statistik für Sozialwissenschaftler [ger]. 4th ed. SpringerLehrbuch. Berlin: Springer; 1993.

30. Barthel H, Gertz H-J, Dresel S, Peters O, Bartenstein P, Buerger K, et al. Cerebral amyloid- $\beta$ PET with florbetaben $(18 \mathrm{~F})$ in patients with Alzheimer's disease and healthy controls: a multicentre phase 2 diagnostic study [eng]. Lancet Neurol. 2011. https://doi.org/10. 1016/S1474-4422(11)70077-1.

31. Veronese M, Bodini B, García-Lorenzo D, Battaglini M, Bongarzone S, Comtat C, et al. Quantification of [(11)C]PIB PET for imaging myelin in the human brain: a test-retest reproducibility study in high-resolution research tomography [eng]. J Cereb Blood Flow Metab. 2015. https://doi.org/10.1038/ jcbfim.2015.120.

32. Marutle A, Warpman U, Bogdanovic N, Nordberg A. Regional distribution of subtypes of nicotinic receptors in human brain and effect of aging studied by (+/-)-3Hepibatidine [eng]. Brain Res. 1998. https://doi.org/10.1016/s0006-8993(98)00558-7.

33. Paterson D, Nordberg A. Neuronal nicotinic receptors in the human brain [eng]. Prog Neurobiol. 2000. https://doi.org/10.1016/s03010082(99)00045-3.

34. Gotti C, Clementi F. Neuronal nicotinic receptors: from structure to pathology [eng]. Prog Neurobiol. 2004. https://doi.org/10.1016/j. pneurobio.2004.09.006.

35. Shimohama S, Taniguchi T, Fujiwara M, Kameyama M. Biochemical characterization of the nicotinic cholinergic receptors in human brain: binding of (-)-3Hnicotine. J Neurochem. 1985. https://doi.org/10.1111/j.1471-4159.1985.tb04029.x.

36. Nordberg A, Alafuzoff I, Winblad B. Nicotinic and muscarinic subtypes in the human brain: changes with aging and dementia [eng]. J Neurosci Res. 1992. https://doi.org/10.1002/jnr. 490310115.

37. Ding Y-S, Fowler JS, Logan J, Wang G-J, Telang F, Garza V, et al. 6-18FFluoro-a-85380, a new PET tracer for the nicotinic acetylcholine receptor: studies in the human brain and in vivo demonstration of specific binding in white matter [eng]. Synapse. 2004. https://doi. org/10.1002/syn.20051.

38. Bhatt S, Hillmer AT, Nabulsi N, Matuskey D, Lim K, Lin S-F, et al. Evaluation of (-)-[18F]Flubatine specific binding: implications for reference region approaches [eng]. Synapse. 2017. https://doi.org/ 10.1002/syn.22016.

39. Braak H, Braak E. Neuropathological stageing of Alzheimerrelated changes [eng]. Acta Neuropathol. 1991;82(4):239-59.

40. Whitehouse PJ, Martino AM, Antuono PG, Lowenstein PR, Coyle JT, Price DL, et al. Nicotinic acetylcholine binding sites in Alzheimer's disease [eng]. Brain Res. 1986. https://doi.org/10. 1016/0006-8993(86)90819-x.

41. Perry EK, Perry RH, Smith CJ, Dick DJ, Candy JM, Edwardson JA, et al. Nicotinic receptor abnormalities in Alzheimer's and Parkinson's diseases [eng]. J Neurol Neurosurg Psychiatry. 1987. https://doi.org/10.1136/jnnp.50.6.806.

42. Martin-Ruiz C, Court J, Lee M, Piggott M, Johnson M, Ballard C, et al. Nicotinic receptors in dementia of Alzheimer, Lewy body and vascular types [eng]. Acta Neurol Scand Suppl. 2000. https://doi. org/10.1034/j.1600-0404.2000.00305.x.

43. Flynn DD, Mash DC. Characterization of L-3Hnicotine binding in human cerebral cortex: comparison between Alzheimer's disease and the normal [eng]. J Neurochem. 1986. https://doi.org/10. 1111/j.1471-4159.1986.tb13113.x.

44. Sihver W, Gillberg PG, Svensson AL, Nordberg A. Autoradiographic comparison of $3 \mathrm{H}(-)$ nicotine, 3Hcytisine and 3 Hepibatidine binding in relation to vesicular acetylcholine transport sites in the temporal cortex in Alzheimer's disease [eng]. Neuroscience. 1999. https://doi.org/10.1016/s0306-4522(99) 00295-x.

45. Perry EK, Morris CM, Court JA, Cheng A, Fairbairn AF, McKeith IG, et al. Alteration in nicotine binding sites in Parkinson's disease, Lewy body dementia and Alzheimer's disease: possible index of early neuropathology [eng]. Neuroscience. 1995. https://doi.org/10. 1016/0306-4522(94)00410-7.

46. Nordberg A, Winblad B. Reduced number of 3Hnicotine and 3 Hacetylcholine binding sites in the frontal cortex of Alzheimer brains [eng]. Neurosci Lett. 1986. https://doi.org/10.1016/03043940(86)90629-4.

47. Hampel H, Bürger K, Teipel SJ, Bokde ALW, Zetterberg H, Blennow K. Core candidate neurochemical and imaging 
biomarkers of Alzheimer's disease [eng]. Alzheimers Dement. 2008. https://doi.org/10.1016/j.jalz.2007.08.006.

48. Kadir A, Almkvist O, Wall A, Långström B, Nordberg A. PET imaging of cortical 11C-nicotine binding correlates with the cognitive function of attention in Alzheimer's disease [eng]. Psychopharmacology. 2006. https://doi.org/10.1007/s00213-0060447-7.
49. Selden NR, Gitelman DR, Salamon-Murayama N, Parrish TB, Mesulam MM. Trajectories of cholinergic pathways within the cerebral hemispheres of the human brain [eng]. Brain. 1998;121(Pt 12):2249-57.

Publisher's note Springer Nature remains neutral with regard to jurisdictional claims in published maps and institutional affiliations.

\section{Affiliations}

\section{Solveig Tiepolt ${ }^{1}$ (1D $\cdot$ Georg-Alexander Becker ${ }^{1} \cdot$ Stephan Wilke $^{1} \cdot$ Diego Cecchin $^{2} \cdot$ Michael Rullmann $^{1}$ • Philipp M. Meyer ${ }^{1}$ • Henryk Barthel ${ }^{1}$. Swen Hesse ${ }^{1}$. Marianne Patt ${ }^{1}$. Julia Luthardt ${ }^{1}$. Gudrun Wagenknecht ${ }^{3}$. Bernhard Sattler ${ }^{1}$ • Winnie Deuther-Conrad ${ }^{4}$ • Friedrich-Alexander Ludwig ${ }^{4}$. Steffen Fischer ${ }^{4} \cdot$ Hermann-Josef Gertz ${ }^{5}$. René Smits ${ }^{6} \cdot$ Alexander Hoepping $^{6} \cdot$ Jörg Steinbach ${ }^{7} \cdot$ Peter Brust $^{4} \cdot$ Osama Sabri ${ }^{1}$}

Georg-Alexander Becker

Georg.Becker@medizin.uni-leipzig.de

Stephan Wilke

stephan.wilke0815@googlemail.com

Diego Cecchin

diego.cecchin@unipd.it

Michael Rullmann

Michael.Rullmann@medizin.uni-leipzig.de

Philipp M. Meyer

Philipp.Meyer@medizin.uni-leipzig.de

Henryk Barthel

Henryk.Barthel@medizin.uni-leipzig.de

Swen Hesse

Swen.Hesse@medizin.uni-leipzig.de

Marianne Patt

Marianne.Patt@medizin.uni-leipzig.de

Julia Luthardt

Julia.Luthardt@medizin.uni-leipzig.de

Gudrun Wagenknecht

g.wagenknecht@fz-juelich.de

1 Department of Nuclear Medicine, University of Leipzig, Liebigstraße 18, 04103 Leipzig, Germany

2 Department of Medicine, University-Hospital of Padova, Via Giustiniani 2, 35128 Padova, Italy

3 Electronic Systems (ZEA-2), Central Institute for Engineering, Electronics and Analytics, Research Centre Juelich, WilhelmJohnen-Straße, 52428 Juelich, Germany
Bernhard Sattler

Bernhard.Sattler@medizin.uni-leipzig.de

Winnie Deuther-Conrad

w.deuther-conrad@hzdr.de

Friedrich-Alexander Ludwig

f.ludwig@hzdr.de

Steffen Fischer

s.fischer@hzdr.de

Hermann-Josef Gertz

Hermann-Josef.Gertz@medizin.uni-leipzig.de

René Smits

smits@abx.de

Alexander Hoepping

hoepping@abx.de

Jörg Steinbach

j.steinbach@hzdr.de

Peter Brust

p.brust@hzdr.de

Osama Sabri

Osama.Sabri@medizin.uni-leipzig.de

4 Helmholtz-Zentrum Dresden-Rossendorf, Research Site Leipzig, Permoserstraße 15, 04318 Leipzig, Germany

5 Department of Psychiatry, University of Leipzig, Semmelweisstraße 10, 04103 Leipzig, Germany

6 ABX advanced biochemical compounds GmbH, Heinrich-GläserStraße 10, 01454 Radeberg, Germany

7 Helmholtz-Zentrum Dresden-Rossendorf, Bautzener Landstr. 400, 01328 Dresden, Germany 